\title{
Identification of Toxigenic Aspergillus Species in Rice Produced in Khuzestan and Mycotoxins in limported Cereals
}

\author{
Razie Ranjbar ${ }^{1}$, Mohammad Roayaei Ardakani ${ }^{1 *}$, Mehdi Mehrabi Kushki², Iraj kazeminezhad ${ }^{3}$
}

1. Department of Biology, Faculty of Science, Shahid Chamran University of Ahvaz, Ahvaz, Iran

2. Department of Plant Protection, Faculty of Agriculture, Shahid Chamran University of Ahvaz, Ahvaz, Iran

3. Department of Physic, Faculty of Science, Shahid Chamran University of Ahvaz, Ahvaz, Iran

\section{ABSTRACT}

Background: Due to their high amount of carbohydrate and enough moisture, cereals are a good environment for the growth of toxigenic fungi. Because of the carcinogenicity and mutagenicity of mycotoxins, preventing them from entering the food chain is essential. Therefore, the present study was conducted to determine the amount and type of contaminated imported cereals and rice produced in Khuzestan province.

Materials \& Methods: In October and November 2015, a total of 50 random samples of rice was collected from paddy fields. Aspergillus were identified based on available diagnostic criteria and PCR. The amount and type of aflatoxin in rice samples and mycotoxins in imported cereals (winter 2015 to autumn 2016) were evaluated by HPLC.

Results: Based on one sample t-test and comparing the mean of mycotoxins contaminating cereals in different seasons with national maximum standard, the amount of mycotoxins in barley and wheat were within the standard range but $\% 8.4$ of corn was higher than the permitted level (ppb5). Analysis of aflatoxins in rice also showed that 16 samples were contaminated with aflatoxin B1. Aspergillus flavus was the major pollutant (\%42.1) isolated from rice.

Conclusion: Aspergillus flavus is the major producer of aflatoxin B1 in domestic rice. Examination of imported cereals also showed high rates of fungal growth and production of secondary metabolites, possibly due to inadequate storage conditions, high temperature and humidity. Therefore, it is recommended to strengthen the monitoring tools in the processing and storage of rice and cereals.

Keywords: Mycotoxin, HPLC, Carcinogenic, Aspergillus, Cereals

Received: 2019/10/08; $\quad$ Accepted: 2020/02/06; Published Online: 2020/02/11

\begin{tabular}{|c|c|}
\hline Corresponding Information: & $\begin{array}{l}\text { Mohammad Roayaei Ardakani, Department of Biology, Faculty of Science, Shahid Chamran University of Ahvaz, Ahvaz, Iran. } \\
\text { Email: roayaei_m@yahoo.com }\end{array}$ \\
\hline (c) $\underset{\mathrm{BY}}{(\mathrm{BY})}$ & $\begin{array}{l}\text { This is an original open-access article distributed under the terms of the Creative Commons Attribution-noncommercial } 4.0 \text { International License which } \\
\text { edistribution of the material just in noncommercial usages with proper citation. }\end{array}$ \\
\hline
\end{tabular}

Use your device to scan and read the article online

Ranjbar R, Roayaei Ardakani M, Mehrabi Kushki M, kazeminezhad I. Identification of Toxigenic Aspergillus Species from Rice of Khuzestan and Mycotoxins in Imported Cereals. Iran J Med Microbiol. 2019; 13 (5) :355-373

Download citation: BibTeX | RIS | EndNote | Medlars | ProCite | Reference Manager | RefWorks

Send citation to: $\otimes$ Mendeley 2 Zotero $\mathbb{H}_{\text {RefWorks }}$

\section{Introduction}

Mycotoxins are low-molecular-weight natural products that are produced by filamentous fungi as secondary metabolites (1). There are five important mycotoxins that are naturally present in crops, including Aflatoxin produced by Aspergillus flavus, ochratoxin produced by Aspergillus ochraceus and Penicillium verrucosum, Zearalenone and doxy-nivalenol produced by Fusarium graminearum, and Fumonisin produced by
Fusarium verticillioides (2). Six of the 18 different types of aflatoxin identified are of major importance, including B1, B2, G1, G2, M1, M2. Aflatoxin B1 has been classified as a Group A carcinogen by world health organization (WHO), for its constant contribution to the pathogenesis of liver cells $(1,5)$. Currently being used to detect a wide variety of mycotoxins, High Performance Liquid Chromatography (HPLC) leads to the production of 
reliable data and accurate, precise and repeatable results, and will usually be of interest to researchers (6).

Although the weather in a particular country may not cause the development of a particular mycotoxin such as aflatoxin, the problem may come from another country in the form of crops such as peanuts and corn.

\section{Materials and Methods}

\section{Isolation of Aspergillus Species}

\section{Collecting Rice Samples}

In November 2015, 50 samples of rice husk from Baghmalek (23 samples of Champa), Shadegan (12 samples of Anbarboo) and Shooshtar (15 samples of Anbarboo) were collected through non-random convenience sampling. About 300 gr of rice husk was collected and transferred to the laboratory in sterile bags.

\section{Isolation of Aspergillus Colonies from Rice Samples}

One hundred rice seeds were randomly selected from each sample after washing and culturing on Sabouraud dextrose agar (SDA), based on colonial appearance and reproductive organs.

\section{Identification of Aspergillus Strains Based on Morphological Traits}

After 5 to 7 days of daily growth of the fungi and the type and shape of the colonies (Figure 1), Aspergillus fungi were identified by mycological and physiological methods according to John I. Pitt Diagnostic Key.

Classification of this group based on morphological identification is a traditional way that is very difficult and can lead to misdiagnosis, especially for Aspergillus niger species, which are a group of morphologically indistinguishable species (8-10).

\section{Identification of Aspergillus Strains Based on ITS Sequencing}

\section{Fungal Mycelium Production and DNA Extraction}

The grown mycelium mass was collected in SDB medium, washed with sterile distilled water and then dehydrated. The mycelium mass was powdered in liquid nitrogen. DNA isolation was performed with the modification of Raeder \& Broda (1985) (with minor modification) $(\mathbf{1 1 , 1 2})$.

Mycelium powder was purified and protein degraded in three successive stages using phenol, chloroform, and isoamyl alcohol. The DNA was finally collected by ethanol precipitation and washed with $70 \%$ ethanol.

\section{ITS Gene Amplification}

The ITS1-F and ITS4-R primer pairs were used to amplify around $600 \mathrm{bp}$ of ITS regions. The reaction was performed in a thermocycler (Biorad) with the following temperature program: $3 \mathrm{~min}$ at $95^{\circ} \mathrm{C}$ and then 35 cycles, $95^{\circ} \mathrm{C}$ for $30 \mathrm{sec}$., $52^{\circ} \mathrm{C}$ for $40 \mathrm{sec}$., $72^{\circ} \mathrm{C}$ for $1 \mathrm{~min}$, and a final extension step at $72^{\circ} \mathrm{C}$ for $5 \mathrm{~min}$.

\section{Measurement and Determination of Mycotoxins Level and Type by HPLC}

\section{Sample Collection}

The analysis of mycotoxins in imported cereal was carried on 50 samples out of 2750 samples referred from Imam Khomeini Port Customs in winter, spring, summer and autumn 2016. It should be noted that the basis for the determination and detection of mycotoxins by the HPLC method was the same in all cases according to the standards of the National Iranian Standards Organization.

\section{Sample Preparation}

Fifty grams of samples were weighed for testing mycotoxins according to Iranian National Standard No. 6872 “Human-Animal Feed, Measurement of Group B and G Aflatoxins", No. 9238 "Cereals and its Products Measurement of Ochratoxin A", No. 9239 "Cereals and Products" Its weights - the zearalenone measurement", and No. 9240 "doxylamine content determination"

\section{Measuring the Amount and Type of Mycotoxins}

The toxin was extracted from the samples by solvent extraction (methanol 80\%). The extract was diluted with Watman filter paper to a certain concentration after being filtered through a sinter filter. Extracts obtained from the immunoaffinity column containing specific antibodies (ZearalaTest ${ }^{\mathrm{TM}}{ }^{\text {, AflaTest }}{ }^{\mathrm{TM}}$, OchraTest ${ }^{\mathrm{TM}}$, DONTest ${ }^{\mathrm{TM}}$ ) were passed at a drop per second rate and the antigen present in the extract was bound to specific antibodies in the column. Injection, isolation, detection, and determination of Mycotoxins was calculated by reversed-phase HPLC columns and derivative and fluorescence detector, through comparison of the standard substrate surface with an unknown specimen, taking into account the dilution factor in ng/g (HPLC device, KNAUER, Germany). In order to calculate the recovery rate of mycotoxin toxins with a concentration of $1.6 \mathrm{ppb}$ in healthy specimens, spiked specimens were read and extracted in a similar manner. Recovery rates of mycotoxins were in the range of $0-6 \%$. This range is acceptable by national standards and indicates that the extraction operations are well performed.

\section{Results}

Investigation and Identification of Aspergillus Isolates from Rice

Of the 19 samples sequenced, 8 isolates (group I) were identified as Aspergillus flavus, 2 isolates (group II) 
as Aspergillus terreus, 1 isolate as Aspergillus nidulans (Group III), 3 isolates as Aspergillus tubingensis, 3 isolates as Aspergillus niger and 1 isolate as Aspergillus $S P$ (Figures 2 and 3).
The ITS region sequences in the studied samples showed $99-100 \%$ similarity to the type strains of any gene in the NCBI database (Table 1).

Table 1. Identification results of isolates based on blast morphology and search and their access number registered in the gene bank

\begin{tabular}{|c|c|c|c|}
\hline \multirow[t]{2}{*}{$\begin{array}{l}\text { Aspergillus has the most } \\
\text { similarity }\end{array}$} & $\begin{array}{l}\text { Isolate name (registered in } \\
\text { GenBank) }\end{array}$ & Gathering location & $\begin{array}{c}\text { Accession Number of } \\
\text { Sequences Registered } \\
\text { for this Study in } \\
\text { GenBank }\end{array}$ \\
\hline & & & ITS \\
\hline \multirow{8}{*}{ Aspergillus flavus } & Sho_R1f & Shooshtar & KY490723 \\
\hline & Sho_R2f & Shooshtar & KY490717 \\
\hline & $B a g \_R 6 f$ & Baghmalek & KY490710 \\
\hline & $B a g \_R 7 f$ & Baghmalek & KY490714 \\
\hline & $B a g \_R 8 f$ & Baghmalek & KY490709 \\
\hline & Bag_R10f & Baghmalek & KY490722 \\
\hline & Sha_R15f & Shadegan & KY490712 \\
\hline & Sha_R18f & Shadegan & KY490711 \\
\hline \multirow{2}{*}{ Aspergillus terreus } & Sha_R12t & Shadegan & KY490721 \\
\hline & Sha_R14t & Shadegan & KY490708 \\
\hline \multirow{3}{*}{ Aspergillus tubingensis } & Sha_R11tu & Shadegan & KY490713 \\
\hline & Sha_R13tu & Shadegan & KY490707 \\
\hline & Sha_R16tu & Shadegan & KY490706 \\
\hline Aspergillus nidulans & Bag_R5ni & Baghmalek & KY490724 \\
\hline \multirow{4}{*}{ Aspergillus niger } & Sho_R4n & Shooshtar & KY490718 \\
\hline & Bag_R9n & Baghmalek & KY490715 \\
\hline & Sha_R17n & Shadegan & KY490720 \\
\hline & Sha_R19n & Shadegan & KY490719 \\
\hline \multirow[t]{2}{*}{ Aspergillus SP } & Sho_R3a & Shooshtar & KY490716 \\
\hline & $\begin{array}{l}\text { *All samples have } 100- \\
\text { 99\% sequence similarity } \\
\text { to standard samples in } \\
\text { the } N C B I \text { database. }\end{array}$ & & \\
\hline
\end{tabular}



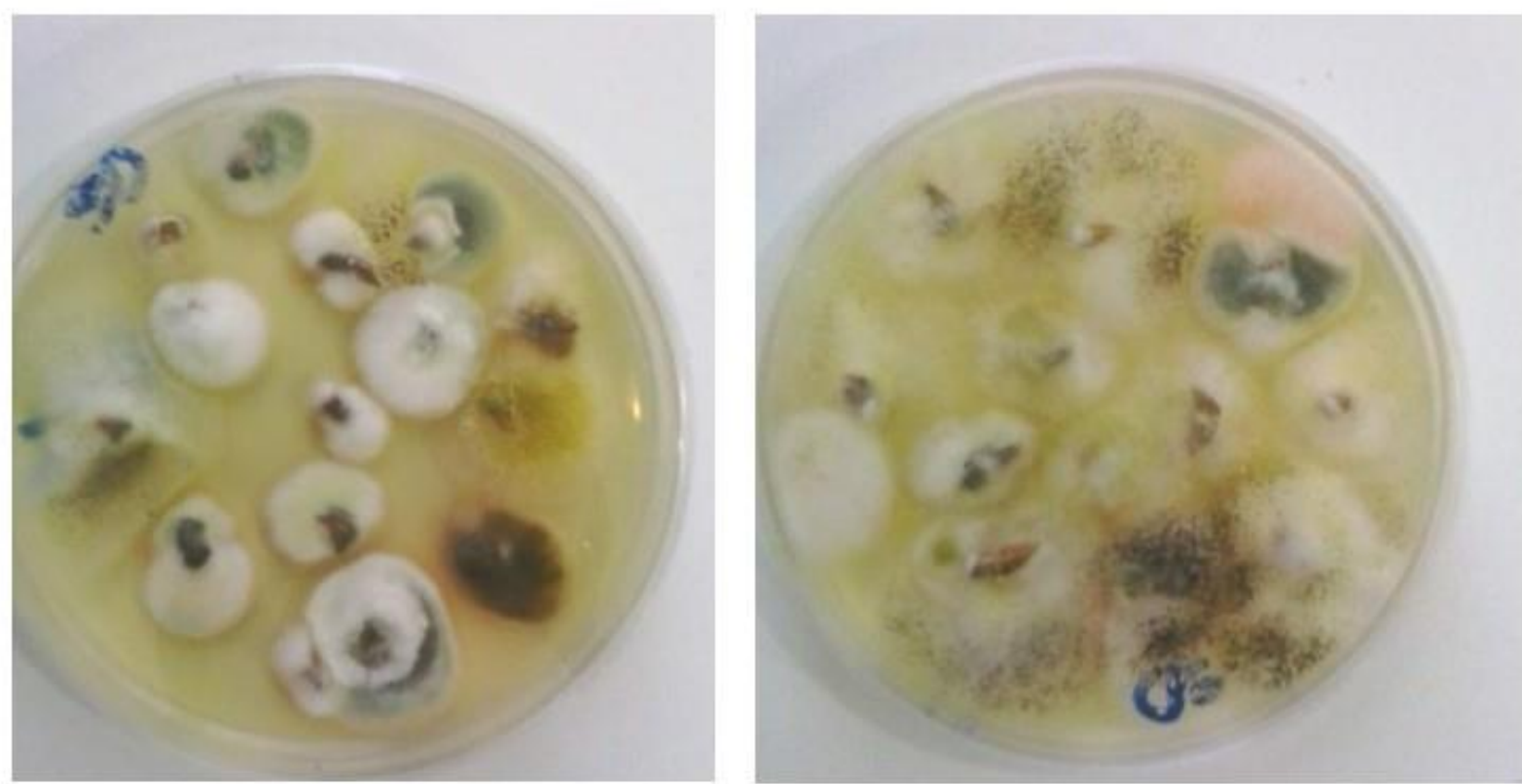

Figure 1. Fungal colonies appearing on the SDA medium at $28^{\circ} \mathrm{C}$ for five days.
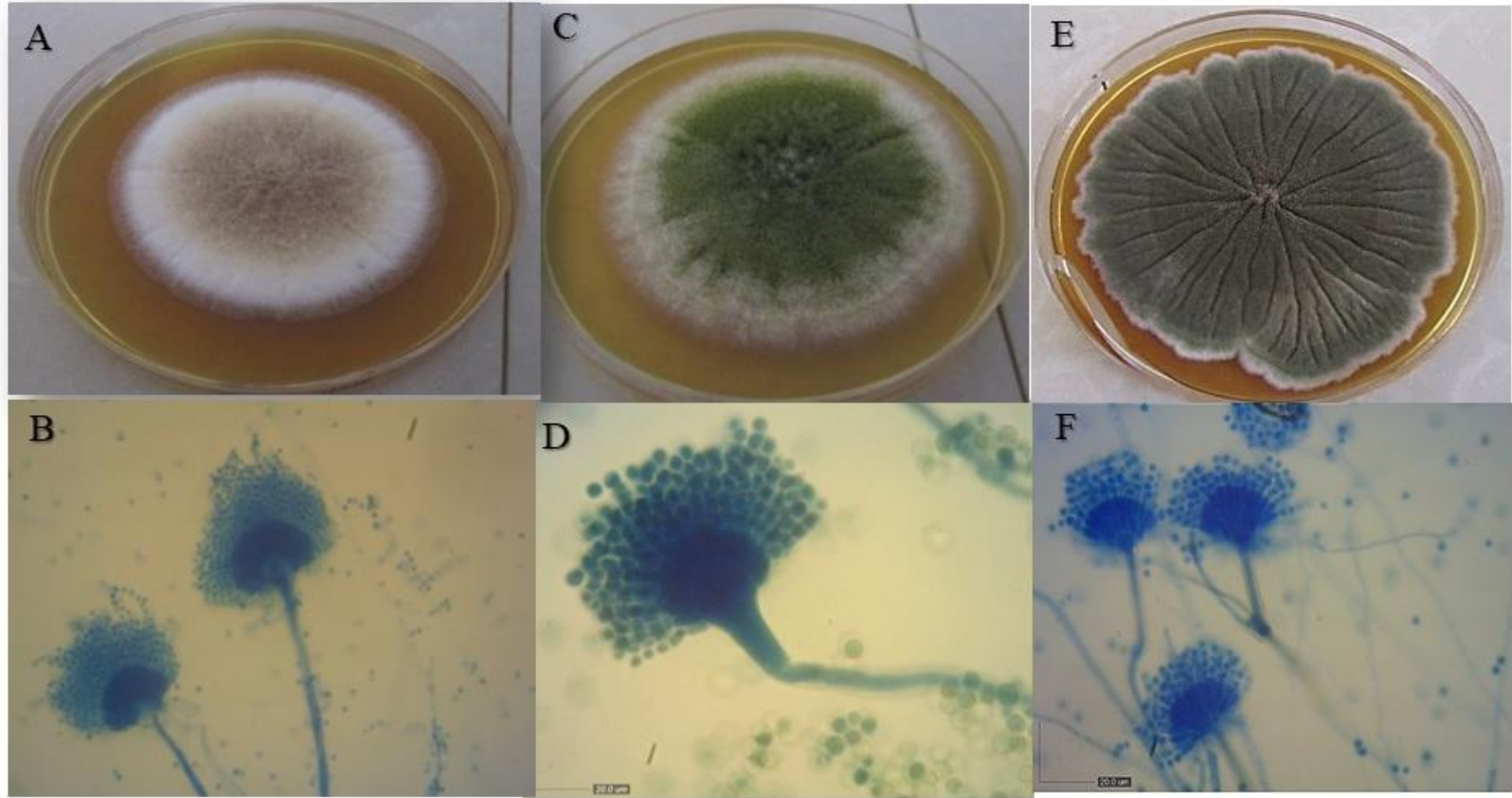

Figure 2. Microscopic image of Aspergillus terreus (A: conidiophore (x40); $B$ : Isolated image on the plate, (Aspergillus flavus; C: conidiophore ( $x 40) \mathrm{D}$ : isolate image on the plate) and Aspergillus nidulans ( $\mathrm{E}$ : conidiophore $(\mathrm{x} 40) \mathrm{F}$ : isolate image on the plate) 


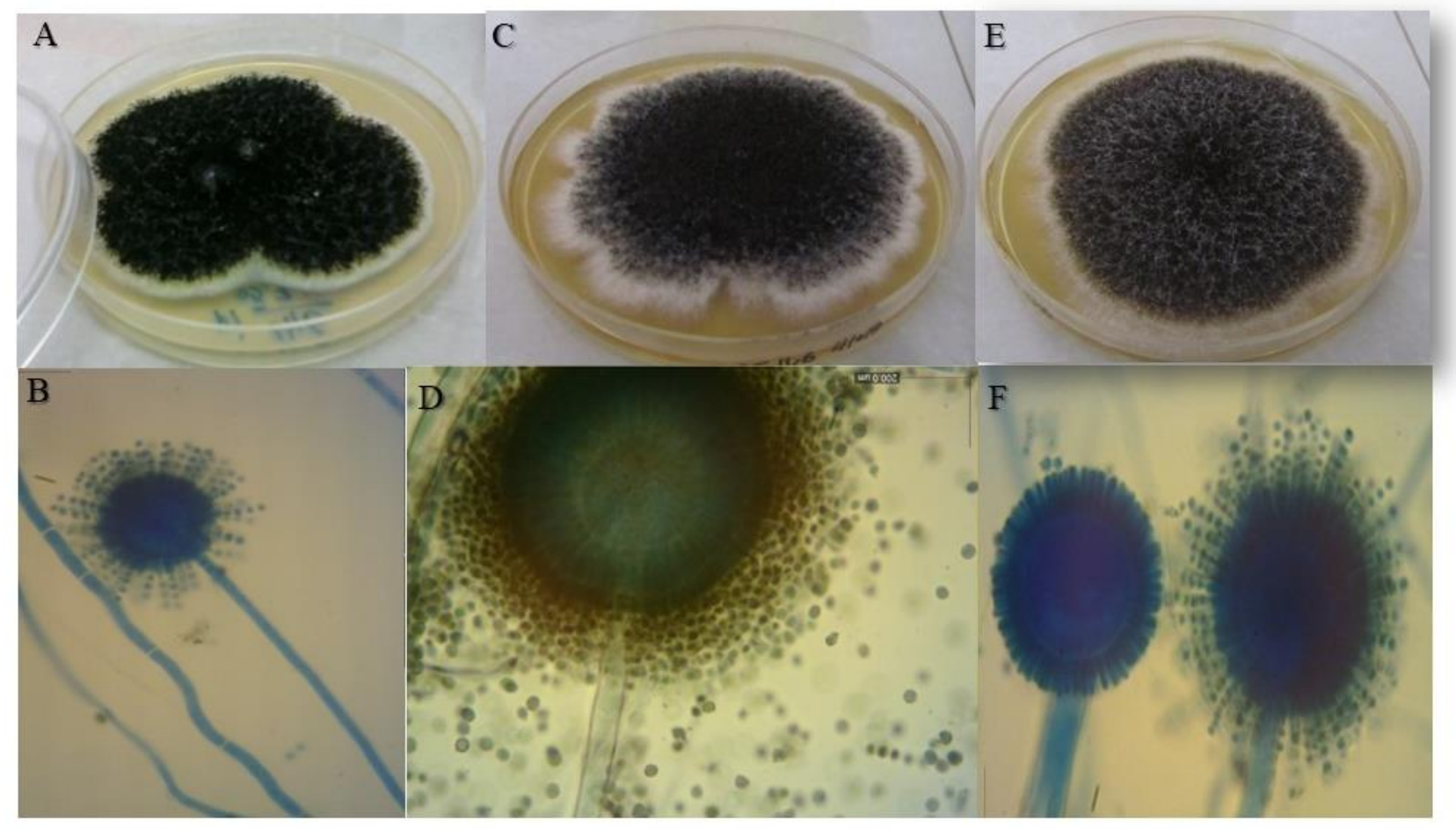

Figure 3. Microscopic image of Aspergillus tubingensis (A: conidiophore (x40) B: Isolated image on the plate), Aspergillus niger (C: conidiophore (x40) D: isolate image on the plate) and Aspergillus sp. (E: conidiophore (x40) F: isolate image on the plate)

\section{Results of Mycotoxins Assay}

The presence of mycotoxins in imported cereals was evaluated qualitatively and quantitatively. From winter to autumn 2016, the type and amount of mycotoxin were measured in 2750 samples of cereals referred to customs in three laboratories in Ahvaz. These included corn, wheat, and barley. The mycotoxins tested on these cereals were aflatoxins, zearalenone, deoxynivalenol, and ochratoxin, according to applicants.

The results of the mean cereal contamination of different mycotoxins and their comparison with the national standard of Iran (5925) are presented in Table 1,2 and 3 respectively (one sample t-test) (Graph pad prism 8 ). The results of statistical analysis showed that the mean of mycotoxins in different grains had a significant difference with the maximum national standard of each mycotoxin $(P<0.05)$

Out of 2111 corn samples, $8.4 \%$ (689) were over contaminated (5 ppb) in AFB1 and 0.4 (9), 3.3 (2), and 0.1 (3) of samples were over contaminated in AFB2, $A F G 1$, and AFG2, respectively.

The levels of ZEN, DON and OTA mycotoxins in 1139 corn samples were lower than the national standard and lower than $200 \mathrm{ppb}, 1000 \mathrm{ppb}$, and $50 \mathrm{ppb}$, respectively. Of 166 wheat samples, $4.2 \%$ (1.2\%) and $1.2 \%(2 \%)$ of samples were contaminated at concentrations below 5 ppb with AFB2 and AFG1, respectively. Also, $13.8 \%$ (16) of the samples were contaminated with OTA at less than $5 \mathrm{ppb}$.

None of the wheat samples showed contamination with DON, ZEN, AFB1, and AFG2. Of the 149 barley samples imported during the sampling interval of this study, only aflatoxins were detected in which no contamination was observed in any of the samples. ANOVA and LSD post hoc tests were used to compare the mean levels of mycotoxins in different months of the year (January to December 2015). According to the results of this test, there was a significant difference between the mean of other mycotoxins in different months of the year $(P<0.05)$.

Of the 50 rice samples tested for aflatoxins, 16 were contaminated with aflatoxin B1, of which only 1 showed more than $5 \mathrm{ppb}$. Samples 2 and 4 were contaminated with AFB2 and AFG1, respectively, $(<5$ $\mathrm{ppb}$ ). The results of the study of mean rice contamination with aflatoxins and comparison with the national standard of Iran are presented in Table 4 (one sample t-test). 
Table 2. Comparison of mean mycotoxin contaminants of imported corn with the national standard of Iran in winter and spring 2016

\begin{tabular}{|c|c|c|c|c|c|c|c|c|c|}
\hline \multirow[b]{2}{*}{ Grains } & \multirow[b]{2}{*}{ mycotoxins } & \multirow{2}{*}{$\begin{array}{l}\text { National } \\
\text { standard } \\
\text { maximum } \\
\text { allowable } \\
\text { (ng /g) }\end{array}$} & \multicolumn{3}{|c|}{ Winter2016 } & \multicolumn{3}{|c|}{ Spring 2016} & \multirow[b]{2}{*}{$\begin{array}{l}\text { Maximum } \\
\text { contamination(ng/g) }\end{array}$} \\
\hline & & & $\begin{array}{l}\text { Average } \\
\text { (ng/g) }\end{array}$ & $\begin{array}{l}\text { Standard } \\
\text { deviation }\end{array}$ & P-value & $\begin{array}{l}\text { Average } \\
\text { (ng/g) }\end{array}$ & $\begin{array}{l}\text { Standard } \\
\text { deviation }\end{array}$ & P-value & \\
\hline \multirow{5}{*}{ Corn } & DON & 1000 & 105.8 & 62.31 & $<0.0001$ & 329.9 & 278.2 & 0.0007 & 868.57 \\
\hline & ZEN & 200 & 13.47 & 13.35 & $<0.0001$ & 33.58 & 4.582 & 0.0003 & 123.731 \\
\hline & OTA & 50 & 0.035 & 0.1385 & $<0.0001$ & 0.71 & 0.6621 & $<0.0001$ & - \\
\hline & AFB1 & 5 & 1.151 & 2.669 & $<0.0001$ & 0.05 & 0.0734 & $<0.0001$ & 169.08 \\
\hline & Total AFs & 20 & 0.8 & 0.973 & $<0.0001$ & 1.25 & 2.253 & $<0.0001$ & 266.77 \\
\hline
\end{tabular}

Table 3. Comparison of mean mycotoxins of imported corn contaminants with the national standard of summer and autumn 2016

\begin{tabular}{|c|c|c|c|c|c|c|c|c|}
\hline \multirow[b]{2}{*}{ Grains } & \multirow[b]{2}{*}{ Mycotoxins } & \multirow{2}{*}{$\begin{array}{l}\text { National } \\
\text { standard } \\
\text { maximum } \\
\text { allowable } \\
\text { (ng /g) }\end{array}$} & \multicolumn{3}{|c|}{ Summer2016 } & \multicolumn{3}{|c|}{ Autumn2016 } \\
\hline & & & $\begin{array}{l}\text { Average } \\
\text { (ng/g) }\end{array}$ & $\begin{array}{l}\text { Standard } \\
\text { deviation }\end{array}$ & P-value & $\begin{array}{l}\text { Average } \\
\text { (ng/g) }\end{array}$ & $\begin{array}{l}\text { Standard } \\
\text { deviation }\end{array}$ & P-value \\
\hline \multirow{5}{*}{ Corn } & DON & 1000 & 496.6 & 175.6 & $<0.0001$ & 0 & 0 & NC \\
\hline & ZEN & 200 & 54.43 & 30.89 & $<0.0001$ & 0 & 0 & NC \\
\hline & OTA & 50 & 0.97 & 0.73 & $<0.0001$ & 0.98 & 0.71 & $<0.0001$ \\
\hline & AFB1 & 5 & 7.03 & 19.23 & 0.28 & 7.553 & 18.52 & 0.0025 \\
\hline & Total AFs & 5 & 11.91 & 32.86 & $<0.0001$ & 11.02 & 29.32 & $<0.0001$ \\
\hline
\end{tabular}

Table 4. Comparison of mean mycotoxins contaminated by imported wheat with Iranian national standard in spring 2016

\begin{tabular}{|c|c|c|c|c|c|c|}
\hline Grains & mycotoxins & $\begin{array}{l}\text { National } \\
\text { standard } \\
\text { maximum } \\
\text { allowable } \\
\text { (ng /g) }\end{array}$ & $\begin{array}{c}\text { Average } \\
\text { (ng/g) }\end{array}$ & $\begin{array}{l}\text { Standard } \\
\text { deviation }\end{array}$ & P-value & $\begin{array}{c}\text { Maximum } \\
\text { contamination } \\
\text { (ng/g) }\end{array}$ \\
\hline \multirow{5}{*}{ Wheat } & DON & 1000 & 0 & 0 & NC & - \\
\hline & ZEN & 200 & 0 & 0 & NC & - \\
\hline & OTA & 5 & 2.67 & 1.053 & $<0.0001$ & 4 \\
\hline & AFB1 & 5 & 0 & 0 & $\mathrm{NC}$ & - \\
\hline & Total AFs & 20 & 0.21 & 0.07 & 0.0016 & - \\
\hline
\end{tabular}


Table 5. Comparison of the average Aflatoxins of Khuzestan rice production contaminants with the national standard of Iran

\begin{tabular}{cccccc} 
mycotoxins & $\begin{array}{c}\text { National standard } \\
\text { maximum allowable } \\
(\mathbf{n g} / \mathrm{g})\end{array}$ & Average(ng/g) & $\begin{array}{c}\text { Standard } \\
\text { deviation }\end{array}$ & P-value & $\begin{array}{c}\text { Maximum } \\
\text { contamination(ng/g) }\end{array}$ \\
\hline AFB1 & 5 & 2.45 & 4.42 & 0.036 & 18.612 \\
\hline Total AFs & 20 & 2.60 & 4.52 & $<0.00001$ & - \\
\hline
\end{tabular}

\section{Discussion}

In this study, Aspergillus susceptible to toxin production was identified and isolated from rice seeds of Khuzestan province (Champa and Anbarboo). Results showed high percentages of Aspergillus flavus (42.1\%) followed by Aspergillus niger, Aspergillus tubingensis, Aspergillus terreus, and Aspergillus nidulans with $21.5 \%, 15.7 \%, 10.52 \%$, and $5.26 \%$, respectively. The findings of Nyongesa et al. (2015), Riba et al. (2010) and Gao et al. (2007) showed that Aspergillus flavus was the main pollutant in oilseeds (pistachio, almond, hazelnut), corn, wheat, cereals, and beans, respectively. The results of the studies of Makun et al. (2007), Amadi et al. (2009) were also consistent with this study $(13,14,15,16,17)$. Because of the saprophyte and widespread toxinogenic fungi such as Aspergillus, rice and cereal products have some relative contamination from the beginning.

The presence of spores and their propagation during transport and storage of grains or contamination of the storage environment with these fungi can lead to the spread of contamination. As Magnussen \& Parsi (2013) found out, drought stress is one of the factors increasing the susceptibility of plants to Aspergillus and as a result of aflatoxin infection (18), the results of this study also suggest that the rate of these fungi can be increased with high heat conditions and increased storage time.

By stage of infection, mycotoxins are "field mycotoxins" produced mainly by Fusarium species and "Mycotoxins in storage", which are produced by Aspergillus and Penicillium species in the pre-harvest period or immediately after harvest during storage $(19,20)$.

The growth of fungi and the accumulation of mycotoxins in food and feed are influenced by various factors which in general relative humidity and temperature are critical factors in the drying and storage period (21). Findings from the study of the amount and type of cereal mycotoxins imported from Imam Khomeini port, mainly from South American countries, showed that the contaminations were not nearly acceptable by Iranian national standard, and corn samples showed the highest levels of mycotoxins, especially aflatoxins. The findings of a study by Mazaheri et al. (2018) also confirmed that corn is most susceptible to mycotoxins, especially aflatoxins (22). The findings of this study indicate that the maximum concentration of mycotoxins is in September and November. These results illustrate the impact of the duration of storage of grain in shipments or in warehouses. This is confirmed by Najafian et al. (2014) (25).

In a study, Ranjbar et al. (2010) showed that Aspergillus and Aflatoxin levels decrease in spring and summer and due to the use of stocked livestock feed and the lack of proper storage conditions, the rate of milk contamination with aflatoxin $\mathrm{M} 1$ increases in the autumn and winter. They stated that inappropriate storage, in addition to contaminating livestock feed with Aspergillus and subsequent aflatoxin production, also transmitted it to packaged milk (26).

Cano-Sancho et al. (2013) also stated that the presence of mycotoxins in food depends on many conditions such as season, weather (temperature, humidity), target area, harvesting method, storage and processing (27). Lahouar et al. (2015) studied the effect of temperature and incubation time on the growth rate of Aspergillus flavus and AFB1 production on sorghum seeds, and reported that the flavus isolate from Tanzanian sorghum has the ability to grow over a wide range of temperatures $\left(15-37^{\circ} \mathrm{C}\right)$, however, aflatoxin production occurs at a lower temperature range $\left(25-37^{\circ} \mathrm{C}\right)(28)$. Ghali et al. (2010) showed that the highest aflatoxin production occurred at $24^{\circ} \mathrm{C}$ but the highest flavus strain growth occurred at $-35^{\circ} \mathrm{C}$ (19).

In this study, the presence of Aspergillus did not indicate the presence of aflatoxins and, conversely, the presence of aflatoxins was not a reason for the presence of Aspergillus. 


\section{Conclusion}

Given the widespread presence of mycotoxins in foods and their harms, especially AFB1, which is a contaminant in food products, control of AFB1 contamination in foodstuffs requires monitoring different factors such as raw materials and food supply, food processing, finished products, and storage.

\section{Acknowledgment}

The authors would like to express their gratitude to the Research Deputy of Khuzestan Agricultural Research Center and Parham Jonoub Company for their cooperation with this study.

\section{Conflict of Interest}

Authors declared no conflict of interests. 


$$
\begin{aligned}
& \text { مجله ميكروبشناسى يزشكى ايران }
\end{aligned}
$$

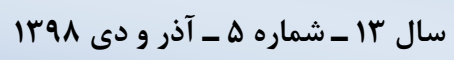

$$
\begin{aligned}
& \text { Journal homepage: www.ijmm.ir }
\end{aligned}
$$

\section{شناسايى كونههاى آسِرزيلوس مولد توكسين در برنجهاى خوزستان و مايكوتوكسينهاى} موجود در غلات وارداتى مولى دو دوبن

راضيه رنجبر'، محمد رعايايى اردكانى ا"، مهدى مهرابى كوشكى '، ايرج كاظمى نزاد؟

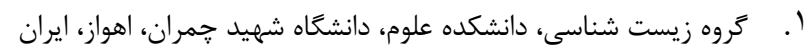

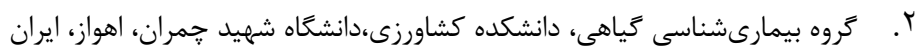

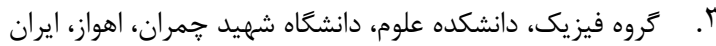

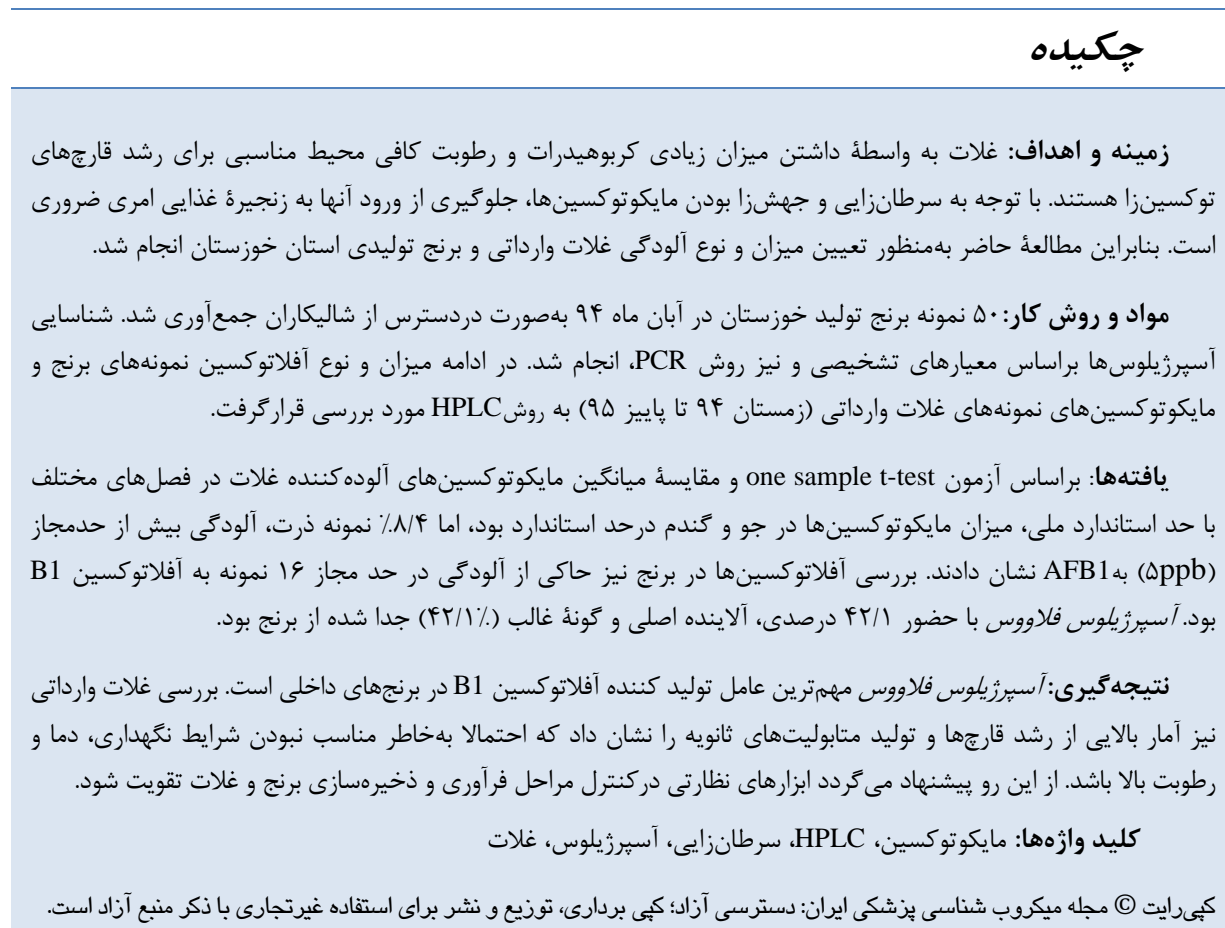

اطلاعات مقاله

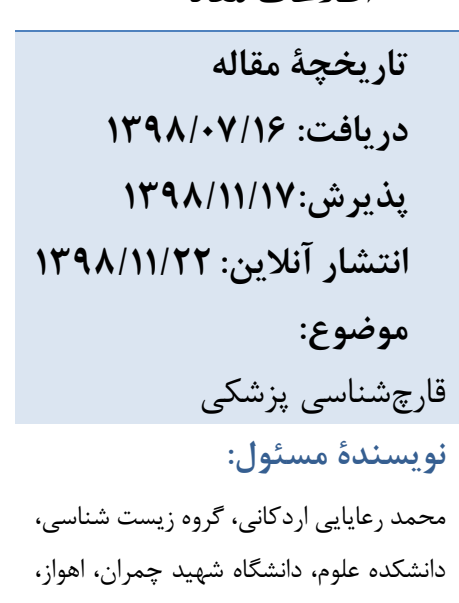

ايران

ايميل: roayaei_m@yahoo.com
Fusarium verticillioides طور طبيعى در محصولات كشاورزى حضور دارند (؟). آسيرزيلوسها از جمله قارجهاى رشتهاى، سايروفيت و

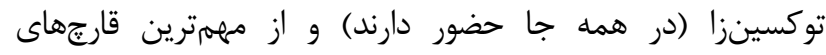
آلوده كننده غلات و مواد غذايى هستند. جنس آسيرزيلوس به راحتى رده بوسيله خصوصيات كونيديوفور شناسايى مىشود اما شناسايى و تمايز كونهها ٍِيجيده است (Y). در سالهاى اخير با استفاده از PCR و شناسايى مولكولى در كنار روشهاى فيلوزنى و ميكروسكوبى

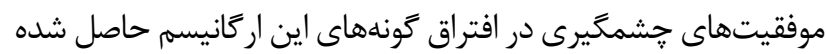
است. از جمله نواحى زنومى كه اغلب براى شناسايى گَونههاى
مايكوتوكسينها Myco (قارج) Toxin (سم) طبيعى با وزن مولكولى گإيين هستند كه بلهوسيلة قارتهاى رشتهاى به عنوان متابوليت ثانويه توليد مىشوند. مايكوتوكسينها اساساً در مسيليوم قارجهاى مولد سم و نيز ممكن است در اسيور اين

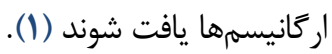

آفلاتوكسين توليدشده بلهوسيلة Aspergillus flavus

أكراتوكسين توليدشده بلوسيلئ Aspergillus ochraceus Penicillium verrucosum بلدوسيلة Fusarium graminearum ، فومونيسين توليد شده بلهوسيلئ 
برنج محصول كشاورزان استان كه در منازل نكمهارى و مورد مصرف غذايى قرار مى كيرند، صورت يذيرفته است.

$$
\text { مواد و روشها }
$$

\section{جداسازى كونههاى آسيرزيلوس}

\section{جمع آورى نمونه جاى برنج}

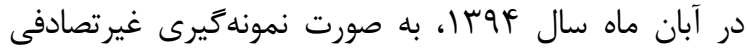

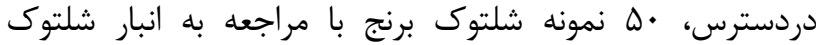

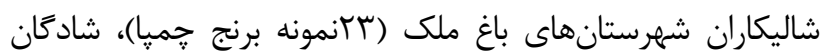

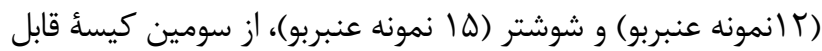

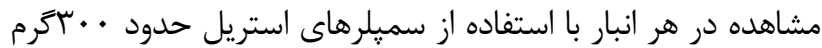

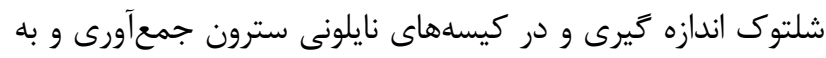

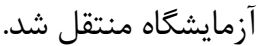

\section{جداسازى يركنههاى آسبرزيلوس از نمونههاى برنج}

از هر نمونه به طور تصادفى ..1 دانه انتخاب وجهت رفع دان

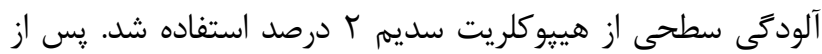

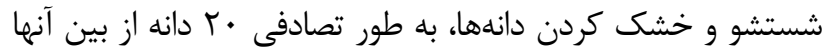
انتخاب و يس از دو نيم كردن در دو ظرف يترى حاوى محيط كشت

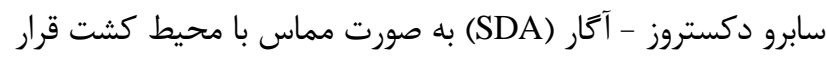

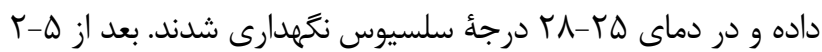
روز، يركَنهاى ظاهر شده اطراف دانهها به ظروف جديد SDA منتسل شدند و بر اساس ظاهر يركنه و اندامهاى توليدمثلى، جدايههاى آسيرزيلوس براى ادامٔ بررسى انتخاب شدند.

\section{خالصسازى جدايههاى آسريرزيلوس}

جدايههاى آسيرزيلوس در ظروف يترى محتوى SDA كشت

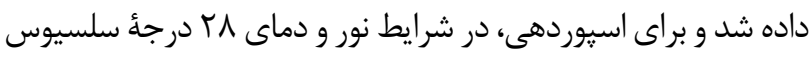
به مدت يك تا دو هفته نكَهدارى شدند. سيس با باستفاده از آب مقطر

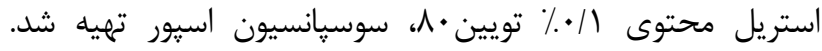
رقتهاى مختلف سوسيانسيون اسيور روى محيط كشت SDA رشد إند داده شد و خالصسازى جدايهها به روش تكاسيور انجام شد.

شناسائى جدايههاى آسيرزيلوس بر اساس صفات ريختشناسى بعد از ه تا V روز و بررسى روزانه، رشد انواع قارجها و نوع و

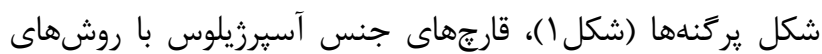
تشخيص قارج شناسى از نظر ريختشناسى و فيزيولوزى بر اساس

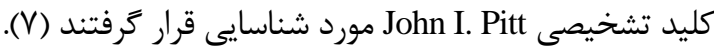

آسيرزيلوس استفاده مىشود، ناحيه ITS است (F). مواد زنتيكى قارجها در هسته و ميتوكندرى قرار دارند كه از قسمتهاى مهمم قارجى زنهايى به نام rDNA هستند. در هر واحد زنى نواحى جداكننده

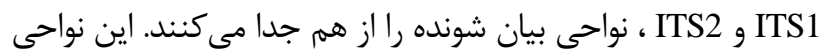
و نواحى جداكننده بين رنى (IGS) به دليل تنوع بالايى كه دارند

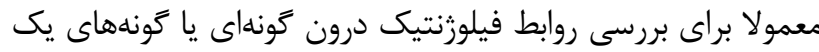

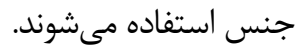

آفلاتوكسينها در درجهٔ اول توسط آسبرزيلوس فلاووس و آسيرزيلوس :إرازيتيكوس در محصولات كشاورزى از جمله غلات

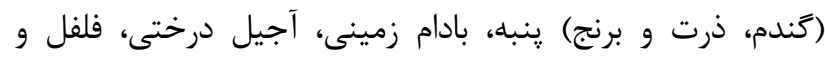

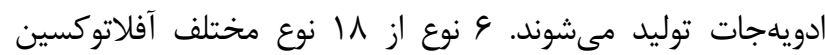

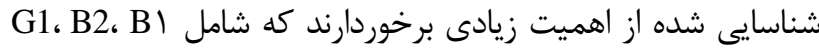

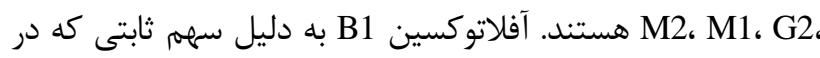

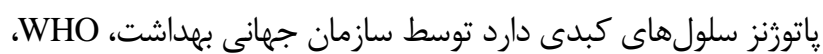

بلهعنوان ماده سرطانزاى كروه A طبقه بندى شده است (ه، (). روشهايى كه جهت تشخيص و تعيين كيفيت مايكوتوكسينها تعريف شدهاند شامل TCC، HPLC، طيفسنجى جرمى، ELISA،

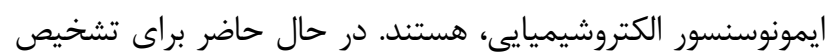

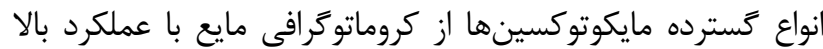

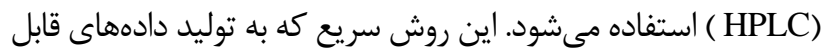

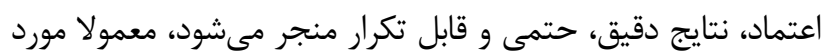
توجه يزوهشكران است (9). كرجه آب و هوا در يك كشـور خاص ممكن است بسط و

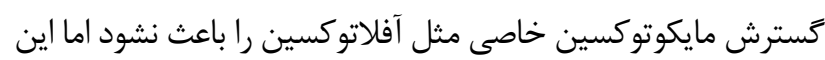
مشكل ممكن است از كشورى ديخر در قالب محصولات كشاورزى مثل مثل

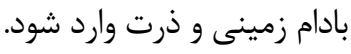
به دليل اينكه غلات وارداتى قبل از مصرف مدتى در انبارها

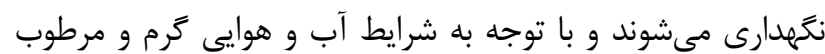
استان خوزستان، شرايط مناسبى براى رشد انواع قارجها فراهم خواهد

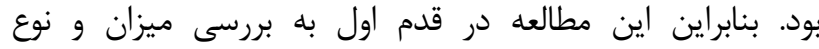

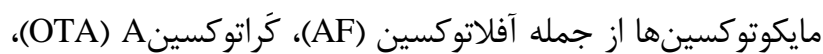
زرالنون (ZEN) و داكسى نيوالنول (DON) در نمونه غلات وارداتى به آنها بندر امام خمينى(ره)، اغلب از كشورهاى آمريكاى جنوبى، كه عمده

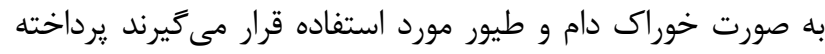
است و از آنجا كه استان خوزستان جز استانهاى توليدكننده برنج در جنوب كشور محسوب مىشود، به بررسى حضور قارجهاى مستعد

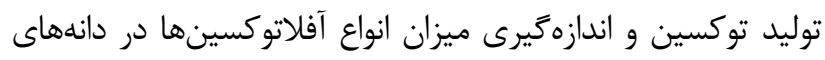



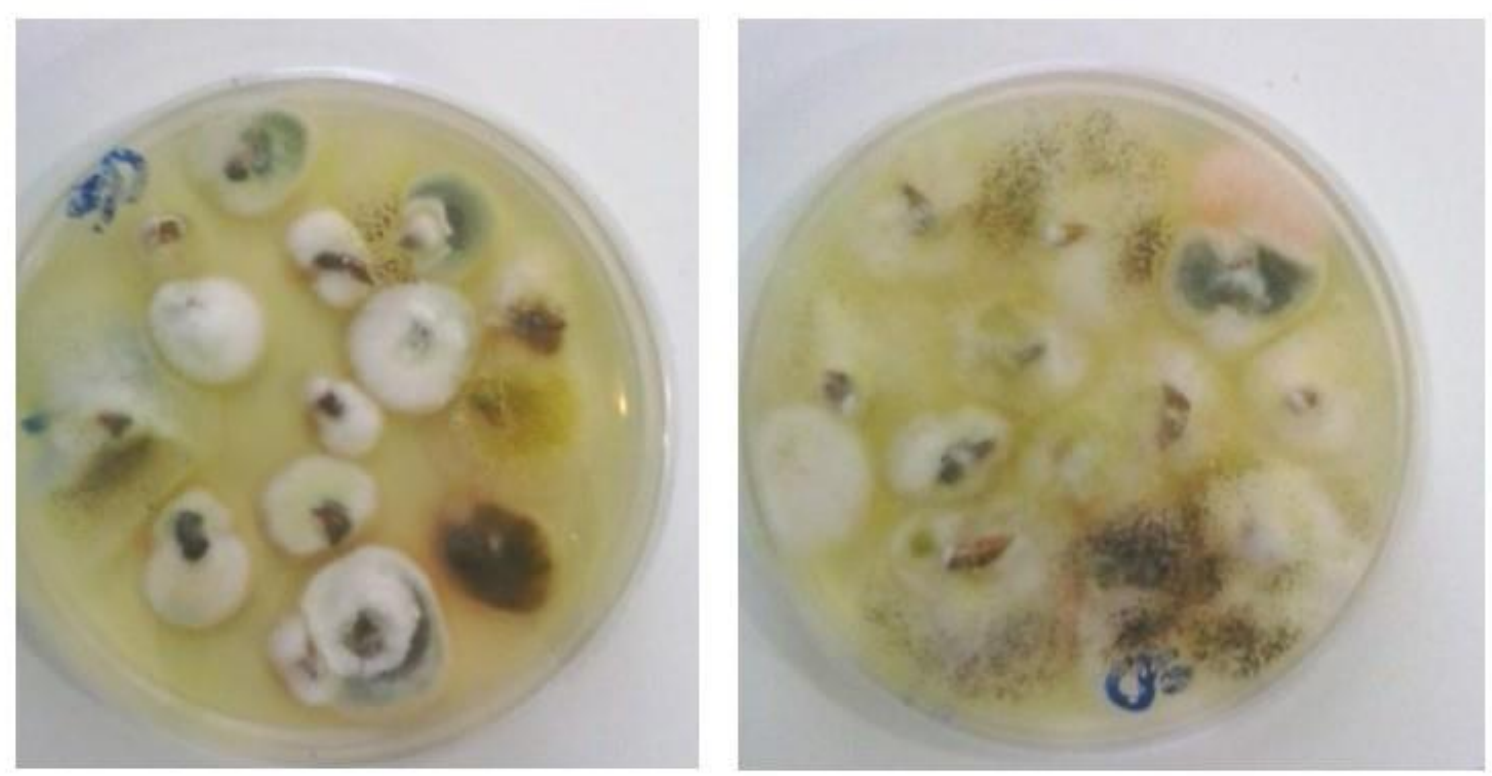

شكل ا. بركنههاى قارجى ظاهر شله روى محيط SDA، با شرايط نتهد/رى دماى 1ץ درجه سلسيوس به مدت ينج روز

خلأ، قيف و كاغذ صافى سترون، توده ميسيليومى رشد يافته در

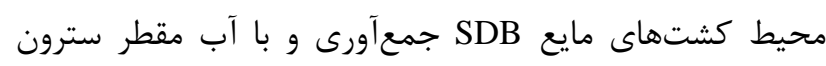

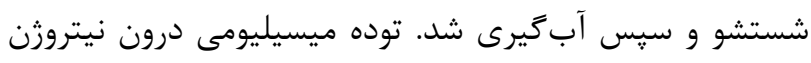

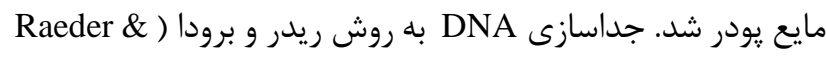

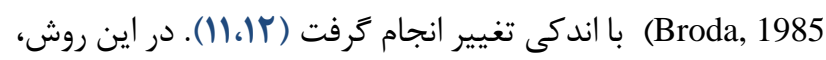

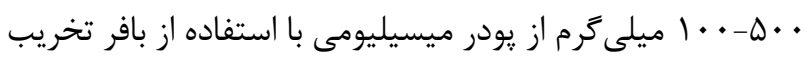

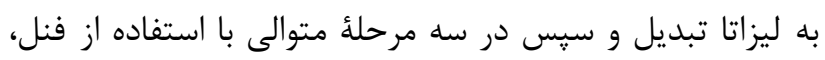

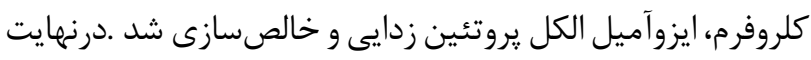

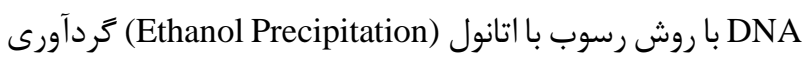
و با اتانول •V V درصد شستشو شد.

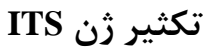

براى تكثير حدود bp ·a از نواحى ITS، از جفت آغازكر

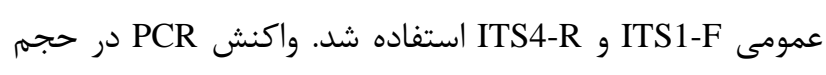

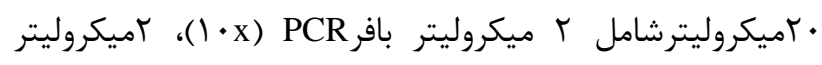

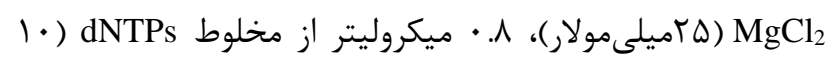

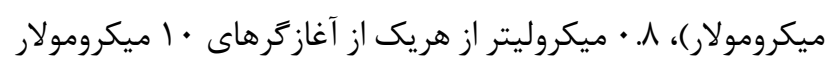

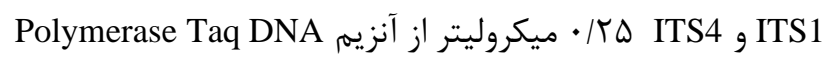

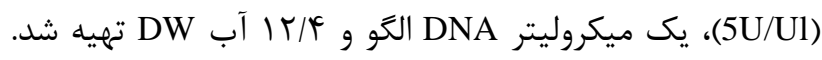
واكنش در دستگاه ترموسايكلر (Biorad) با برنامؤ دمايى زير انجام

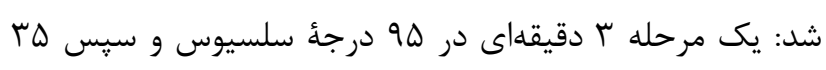

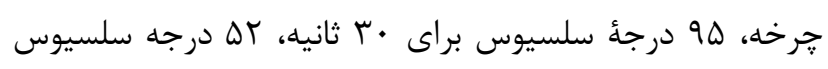

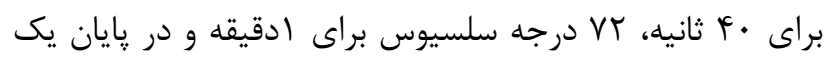

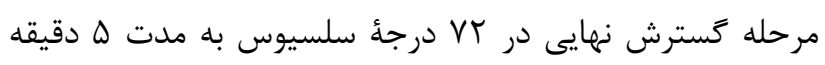

خصوصيات ميكروسكويى جدايهها با استفاده از كشت قارج

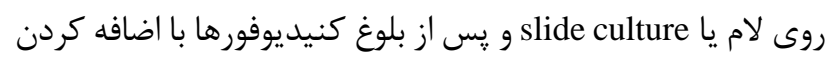

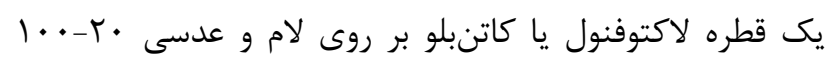

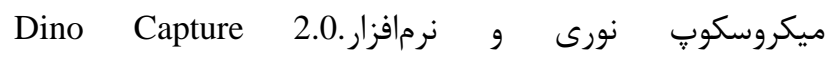
version1.5.11.A

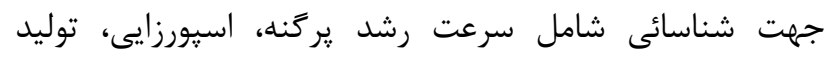

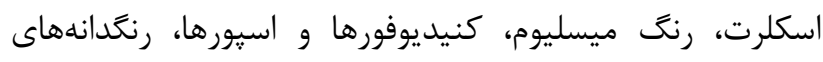

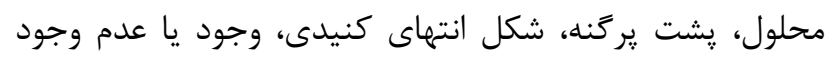

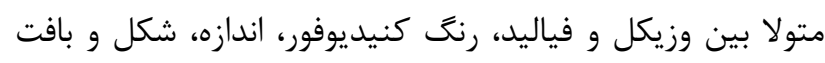

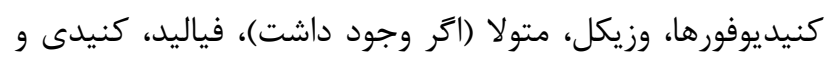

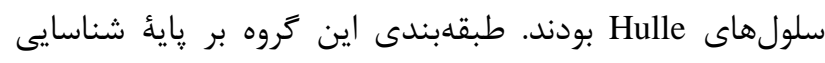

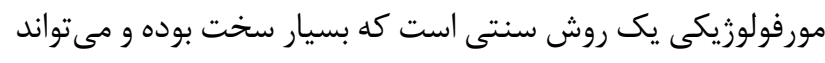

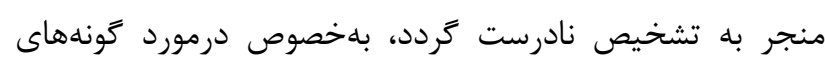

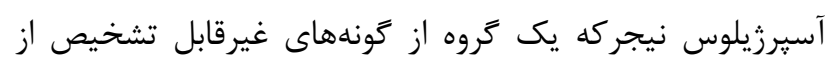

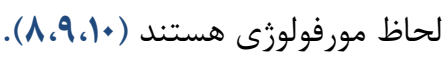
شناسائى جدايههاى آسرِريلوس بر اساس توالىيابى ناحيه ITS

\section{توليد ميسيليوم قارجى و استخراج DNA}

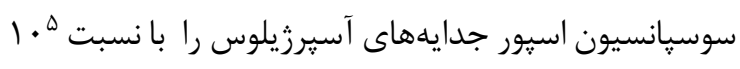

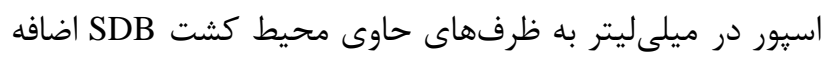

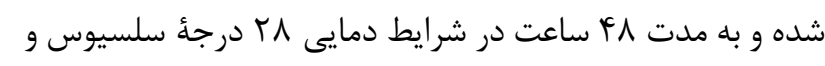

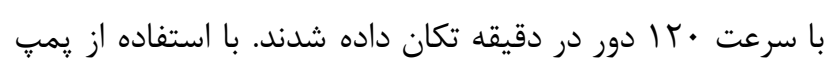


به روش HPLC در تمام موارد يكسان و بر اساس استانداردهاى

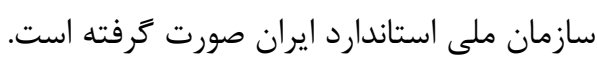

\section{آماده سازى نمونهها}

•

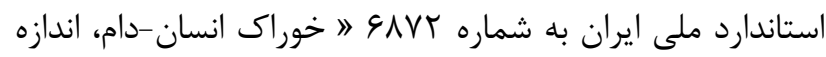

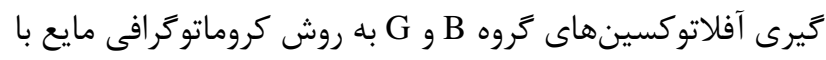

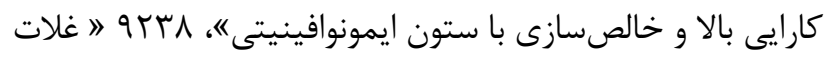

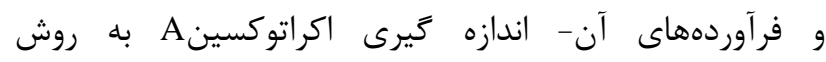

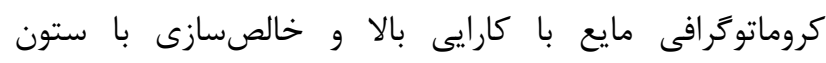

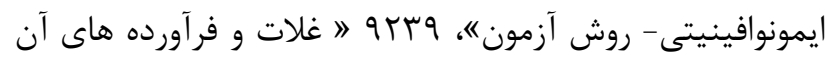

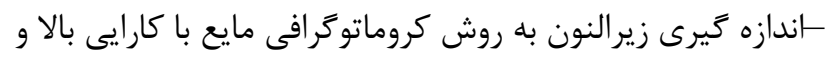

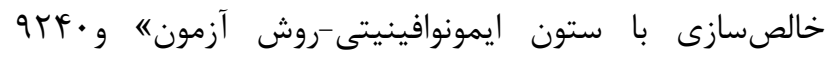

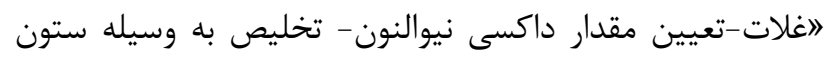

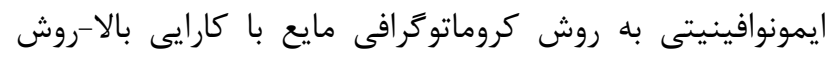

$$
\text { آزمونه توزين شد. }
$$

\section{اندازهيرى ميزان و نوع مايكوتوكسينها}

استخراج توكسين از نمونهها توسط حلال استخراج

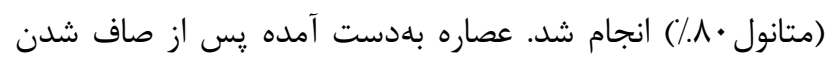

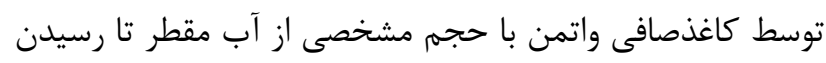

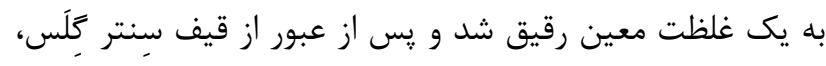

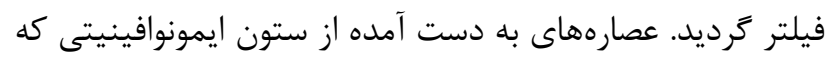

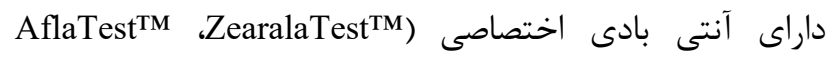
(DONTest ${ }^{\mathrm{TM}}$ ، OchraTest ${ }^{\mathrm{TM}}$ ،

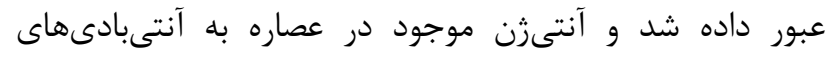

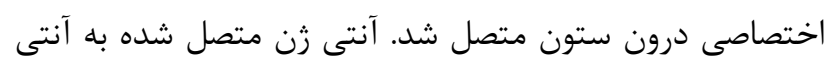

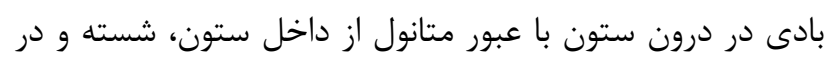

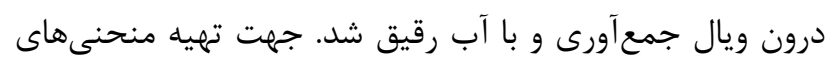

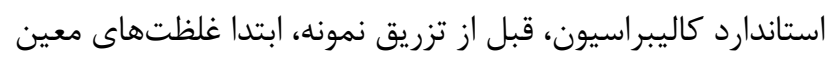

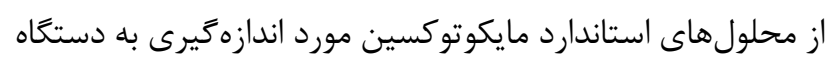
(KNAUER, Germany) HPLC

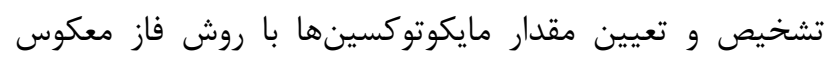

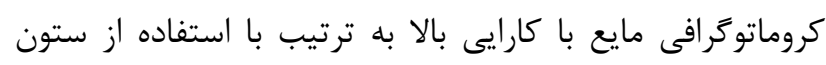

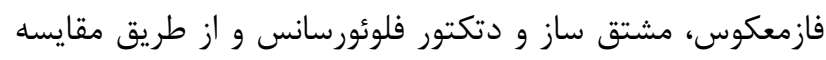

انجام كرفت. محصول PCR (باميكروليتر) پِ از مخلوط كردن با

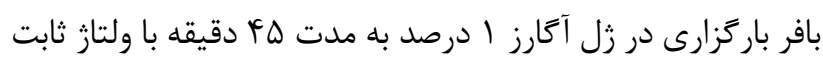

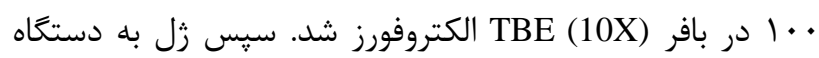

$$
\text { زلداك منتقل و عكسبردارى صورت كرفت. }
$$

\section{خالصسازى قطعههاى افزايشى و توالىيابى}

محصولات PCR مربوط به هر جدايه به روش رسوب با اتانول

تغليظ و شستشو شد. بدين منظور، / / • حجم محصول، استات

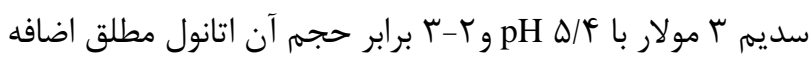

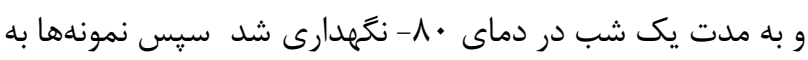

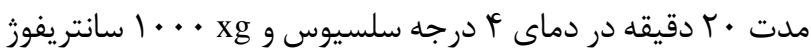

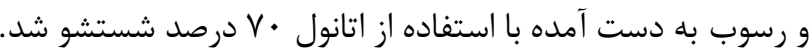

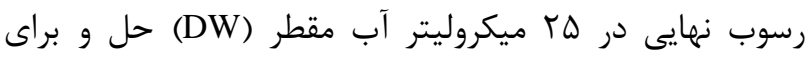

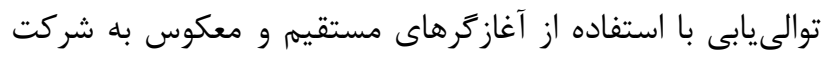

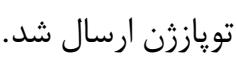

توالىهاى بلهدست آمده با نرمافزار BioEdit ver4.0.6.2 ويراستارى و با نرمافزار

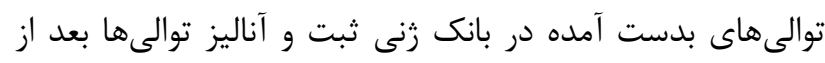

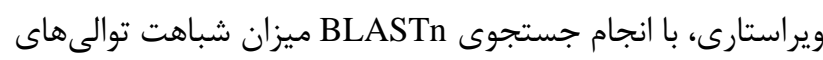

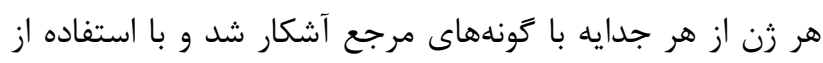

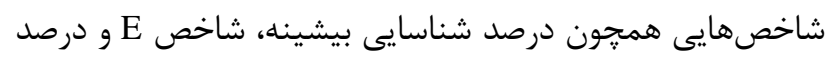
يوشش توالى، جدايهها شناسايى شدند (جدول دماند (). اندازهيرى و تعيين ميزان و نوع مايكوتوكسينها به روش

HPLC

\section{جمع آورى نمونه}

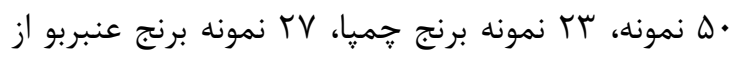

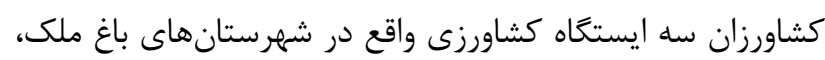

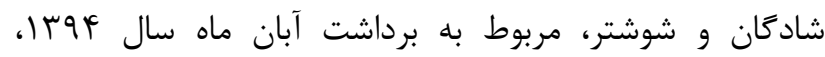

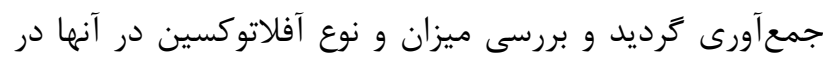

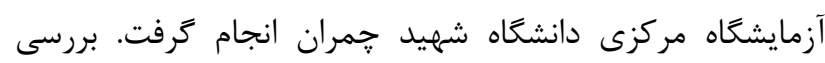

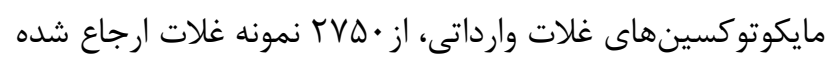

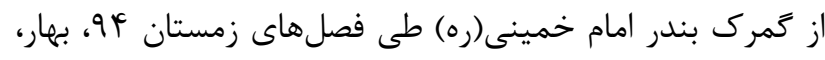

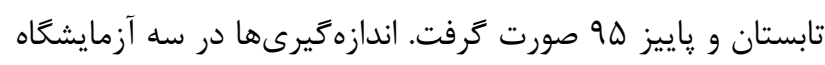

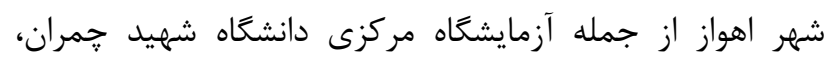

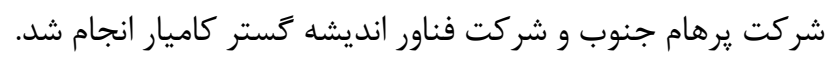
لازم به ذكر است كه كه اساس تعيين و تشخيص مايكوتوكسينها 

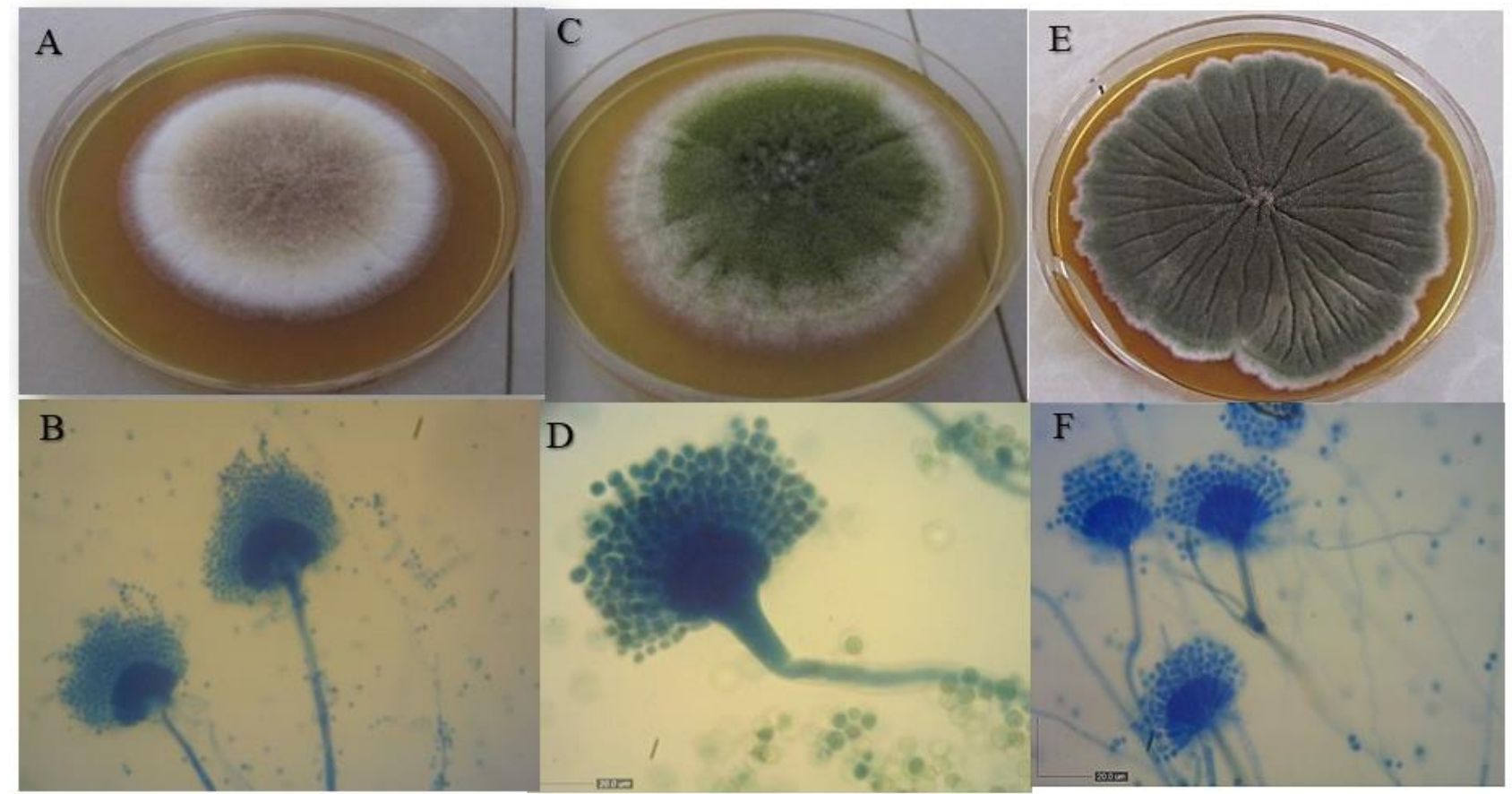

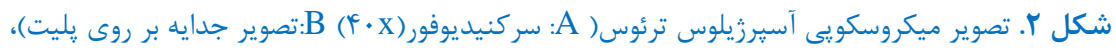

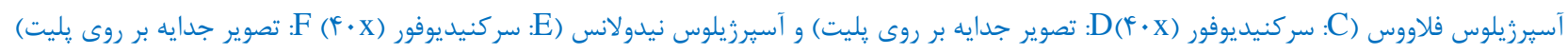

تكثير گرديد و براى تمامى جدايهها يك باند به اندازه تقريبى

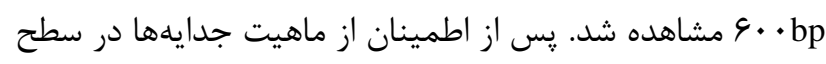

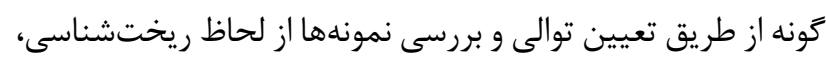

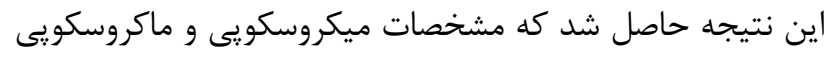

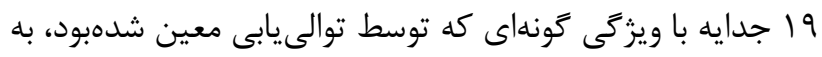
طور كامل تطابق داشتند.

بدين ترتيب از 19 نمونهاى كه تعيين توالى شدند، هشت

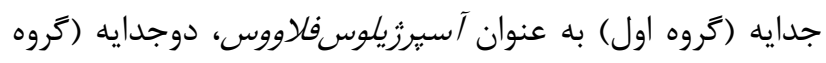

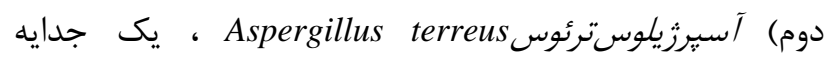

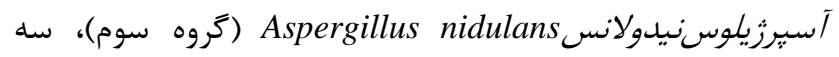

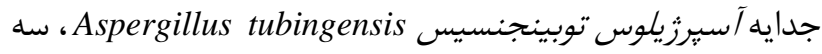
جدايه آسبرزيلوس نيجر Aspergillus niger و يكى جدايه به به عنوان آسيرزيلوس SP تشخيص داده شد (شكل آوّا). توالى ناحيه ITS

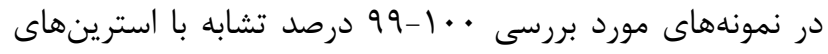

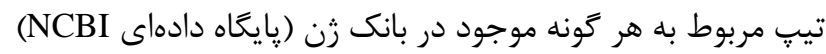

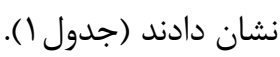

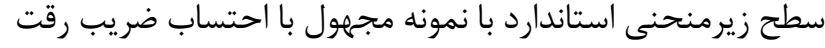

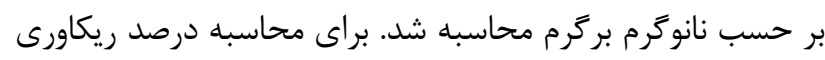

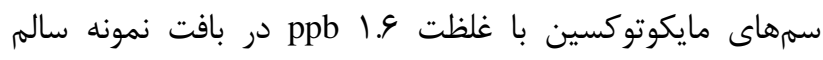

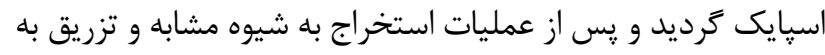

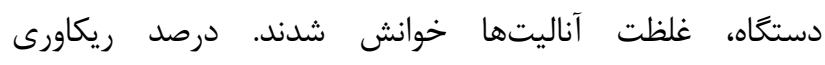

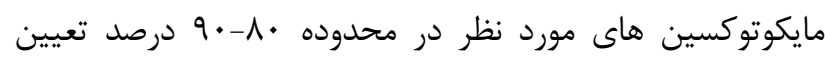

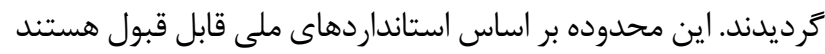
و نشان مى دهد كه عمليات استخراج بخوبى انجام شده است.

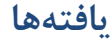

\section{بررسى و شناسايى جدايههاى آسيرزيلوس از برنج}

از • له نمونه برنج مورد بررسى ڤس از انجام مراحل جداسازى

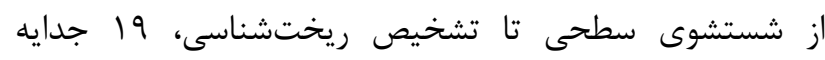

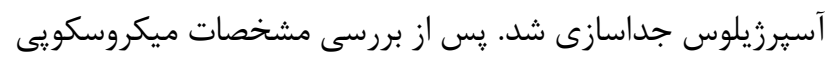

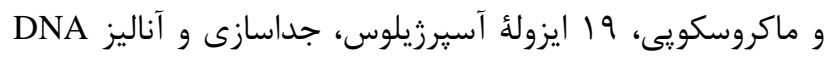

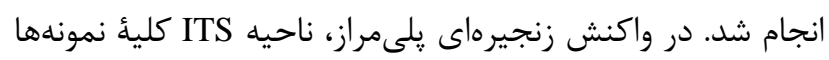


جدول 1. نتايج شناسايى جدايهها براساس ريختشناسى و جستجوى بلاست و شماره دسترسى ثبت شده مربوط به آنها در بانك ثن

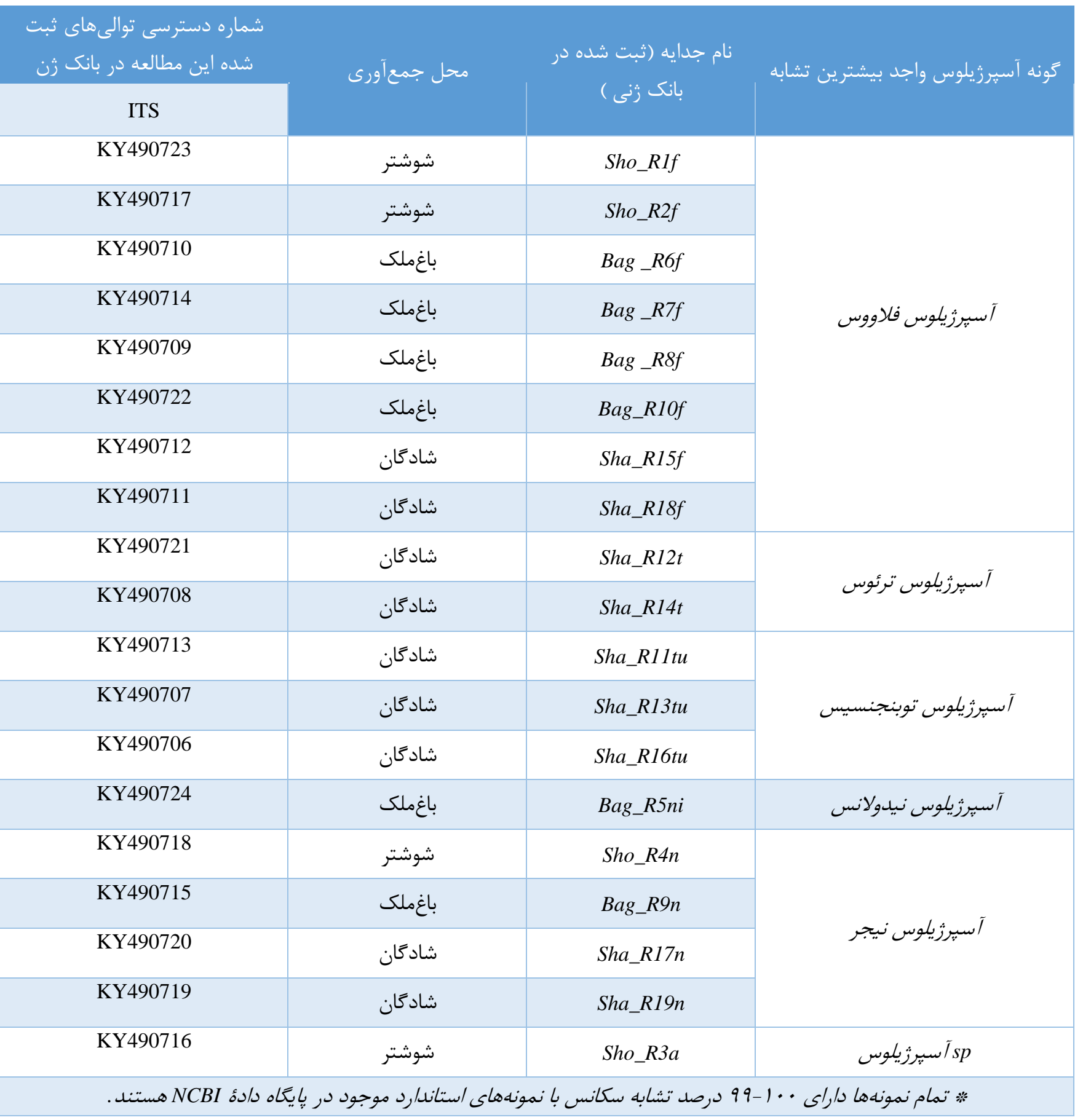




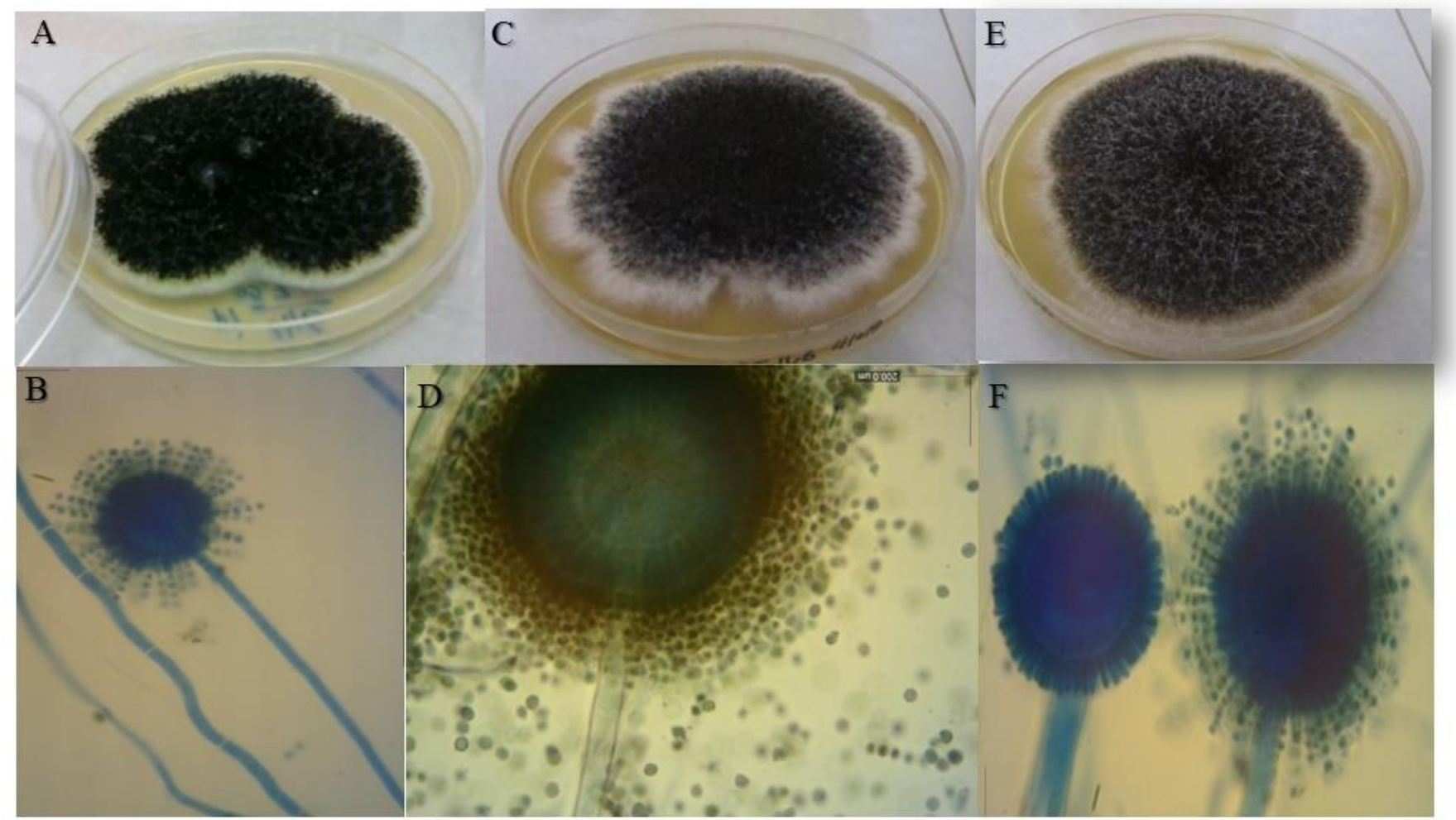

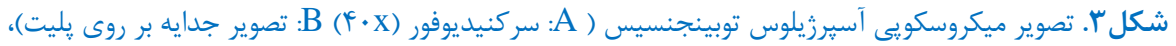

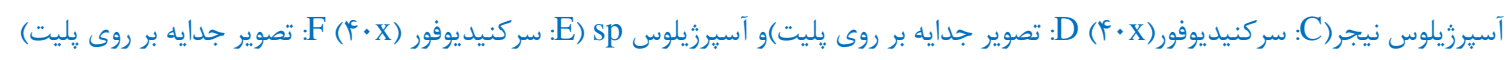

از

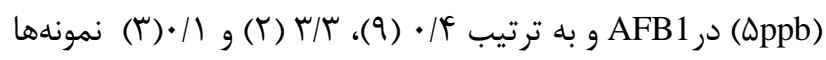

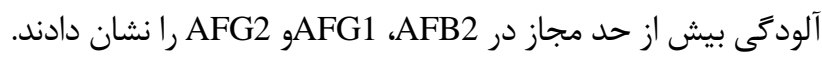

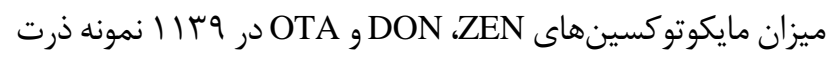

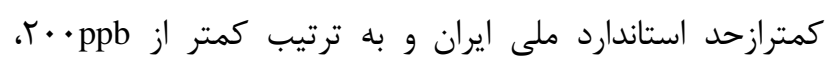

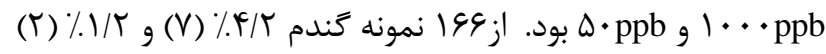

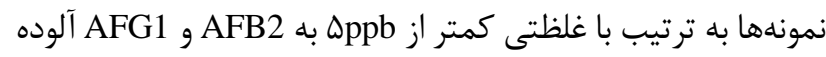

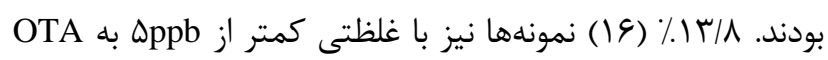

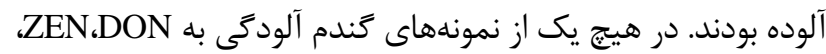

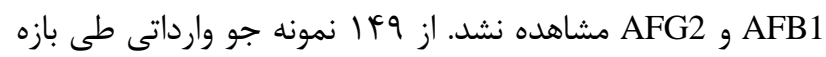
زمانى جمعآورى نمونههاى اين مطالعه، تنها ميزان آفلاتوكسينها

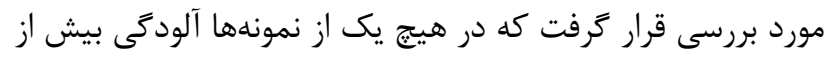
حد مجاز مشاهده نشد. به منظور مقايسه ميانكين سطوح

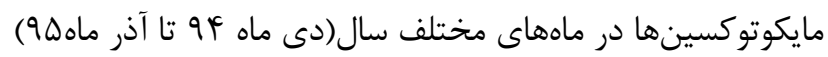

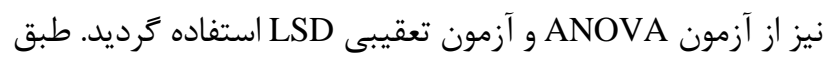

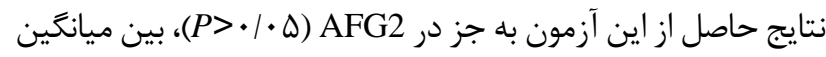

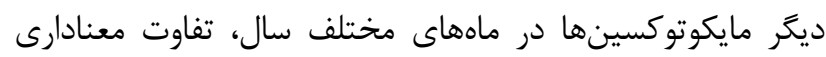

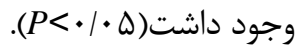

\section{نتايج حاصل از بررسى مايكوتوكسينها}

حضور مايكوتوكسينها در غلات وارداتى و نيز برنج توليدى

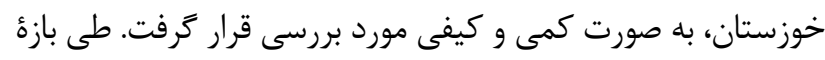

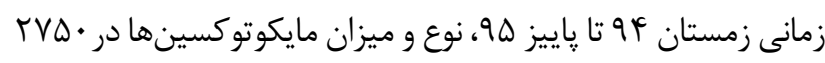

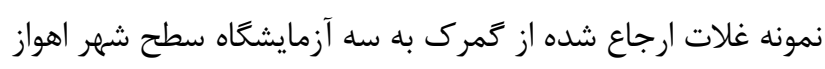

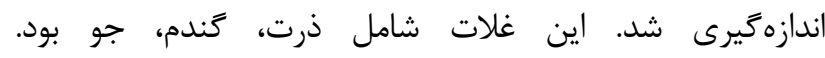

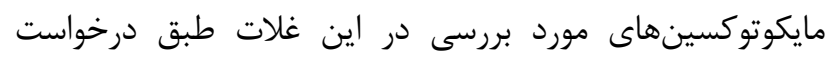

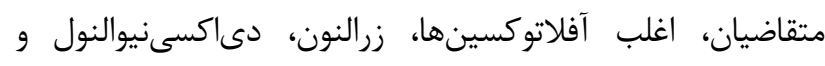
أكراتوكسين بود.

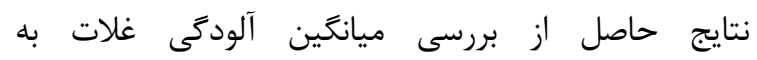

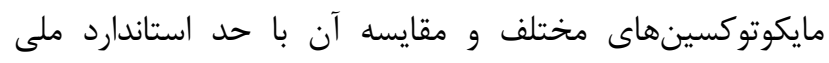

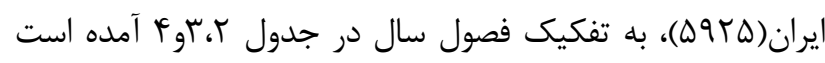
(آزمون (Traph pad prism8)(one sample t-test) آناليز آمارى نشان مىدهد ميانكين مايكوتوكسينها در غلات

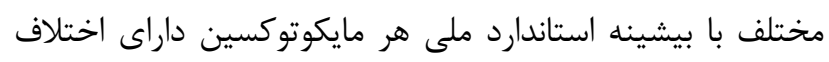

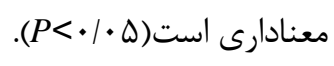


نتايج حاصل از بررسى ميانگين آلودكى برنج به آفلاتوكسينها

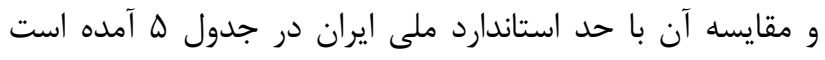
(آزمون (one sample t-test)

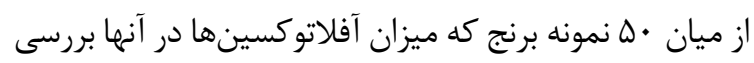

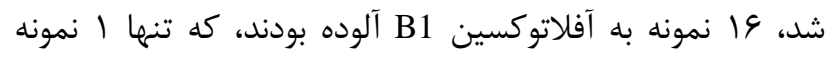

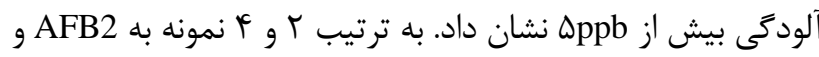

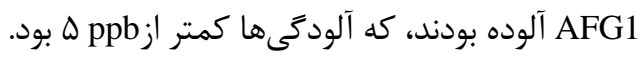

جدول r. مقايسه ميانكَين مايكوتوكسينهاى آلوده كننده ذرت وارداتى با حد استاندارد ملى ايران در زمستان 9 و بهار هو

\begin{tabular}{|c|c|c|c|c|c|c|c|c|c|}
\hline \multirow[b]{2}{*}{ غلات } & \multirow[b]{2}{*}{ مايكو توكسينها } & \multirow[b]{2}{*}{$\begin{array}{c}\text { بيشينه } \\
\text { مجازازدارد } \\
\text { ملى } \\
\text { (g/ng) }\end{array}$} & \multicolumn{3}{|c|}{ زمستان وF } & \multicolumn{3}{|c|}{ 9هار } & \multirow[b]{2}{*}{$\begin{array}{l}\text { بيشينه } \\
\text { (آلودَى } \\
\text { (g/ng) }\end{array}$} \\
\hline & & & $\begin{array}{l}\text { ميانكَين } \\
\text { (g/ng) }\end{array}$ & معيار & P-value & ميانكَين & معيار & $\mathrm{P}$-value & \\
\hline \multirow{5}{*}{ ذرت } & DON & $1 \cdots$ & $1 \cdot \Delta / \Lambda$ & ST/TI & $<\cdot|\cdot \cdot|$ & $r Y q / 9$ & TVN/T & $\cdot 1 \cdot \cdot v$ & $\wedge \& \wedge / \Delta \vee$ \\
\hline & ZEN & $r .$. & $\mid r / A V$ & $\mid r / \pi \Delta$ & $<\cdot|\cdot \cdot|$ & $r r / \Delta \Lambda$ & F/DAT & $\cdot / \cdot r$ & $|r r / V H|$ \\
\hline & OTA & $\Delta \cdot$ & $\cdot 1 \cdot r \Delta$ & $\cdot / 1 r \wedge \Delta$ & $<\cdot|\cdot \cdot|$ & $\cdot|V|$ &.$|994|$ & $<\cdot 1 \cdot \cdots \cdot$ & - \\
\hline & AFB1 & $\Delta$ & $1 / / D 1$ & $r / 999$ & $<\cdot|\cdot \cdot|$ & $\cdot 1 \cdot \Delta$ & $\cdot 1 \cdot V H Y$ & $<\cdot|\cdot \cdot|$ & $\mid 99 / \cdot 1$ \\
\hline & Total AFs & $r \cdot$ & $\cdot 11$ & $.19 V \pi$ & $<\cdot|\cdot \cdots|$ & $1 / \pi \Delta$ & r/TaT & $<\cdot|\cdots \cdot|$ & r\&\&/VV \\
\hline
\end{tabular}

جدول ب. مقايسه ميانكَين مايكوتوكسينهاى آلوده كننده ذرت وارداتى با حد استاندارد ملى ايران در تابستان و پاييزهوج

\section{بإييز}

\section{P-value}

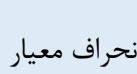

ميانكين (g/ng)

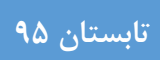

$<\quad<\cdot \cdots 1$

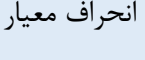

$<\cdot / \cdot \cdot 1$

IVQ/9

$r \cdot 119$

$\cdot 191$

$<\cdot / \cdots)$

$\cdot / N r$

$19 / 4 r$

$11 / \cdot r \quad<\cdot 1 \cdot \cdots 1 \quad$ rT/Ag

rQ/4r

$\cdot \cdot \cdot 1$

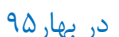

\section{$9 \Delta$ بهار}

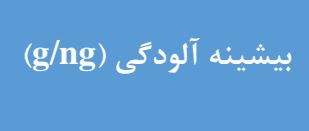

$$
\text { P-value }
$$

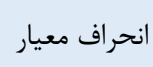

ميانكَين

(g/ng)

\begin{tabular}{|c|c|c|c|c|c|c|}
\hline & & & (g/ng) & ملى & & \\
\hline- & $\mathrm{NC}$ & - & - & $1 \cdots$ & DON & \multirow{5}{*}{ كَندم } \\
\hline- & $\mathrm{NC}$ & - & - & $r \ldots$ & $\mathrm{ZEN}$ & \\
\hline$p$ & $<\cdot 1 \cdot \cdots \cdot 1$ & r & $r / 9 V$ & $\Delta$ & OTA & \\
\hline- & $\mathrm{NC}$ & . & - & $\Delta$ & AFB 1 & \\
\hline- & $\cdot 1 \cdot 19$ & $\cdot 1 \cdot V$ & $\cdot|r|$ & $r \cdot$ & Total AFs & \\
\hline
\end{tabular}

\section{بيشينه (g/ng)}

محاز استاندارد

مايكوتوكسينها

غلات بيشينه مجاز

(g/ng)

DON

r. .

ZEN

OTA

AFB1

Total AFs 
جدول ه. مقايسه ميانكين آفلاتوكسينهاى آلودهننده برنج توليدى خوزستان با حد استاندارد ملى ايران

\begin{tabular}{|c|c|c|c|c|c|}
\hline بيشينه آلودتى (g/ng) & P value & انحراف معيار & $\begin{array}{l}\text { ميانگين } \\
\text { (g/ng) }\end{array}$ & بيشينه مجاز استاندارد & مايكو توكسينها \\
\hline$|N / 9| T$ & צ & $\varepsilon / \varepsilon r$ & $r / \leqslant 0$ & $\Delta$ & AFB1 \\
\hline - & $<\cdot|\cdots+|$ & $\varepsilon / 0 Y$ & $r / T$. & $r$. & Total AFs \\
\hline
\end{tabular}

بحث

كلى رطوبت نسبى و درجه حرارت به عنوان عوامل بحرانى در دوره خشك شدن و ذخيره سازى مطرحاند (Y)). يافتههاى حاصل از بررسى ميزان و نوع مايكوتوكسينهاى غلات وارداتى از بندرامام

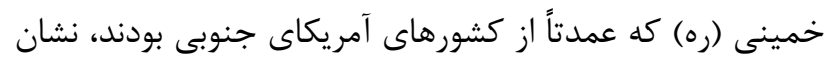
داد كه آلودَّىها طبق استاندارد ملى ايران، تقريباً در حد قابل قبولى قرار نداشتند و نمونههاى ذرت بيشترين ميزان آلودكى به

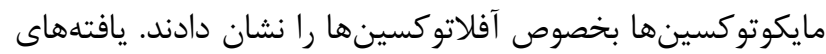
مطالعه Mazaheri و همكاران (1/|•r) نيز تاييدكرد كه ذرت بيشترين حساسيت به مايكوتوكسينها بخصوص آفلاتوكسينها

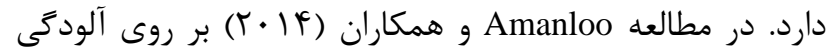

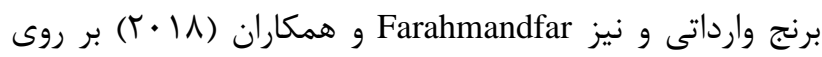

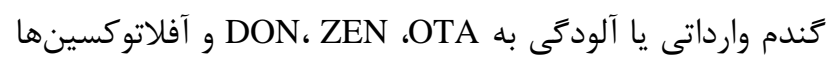

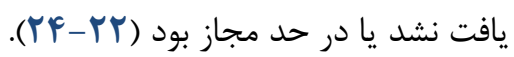

يافتههاى اين مطالعه حاكى از آن است كه حداكثر غلظت مايكوتوكسينها مربوط به ماههاى شهريور و آبان است. اين نتايج

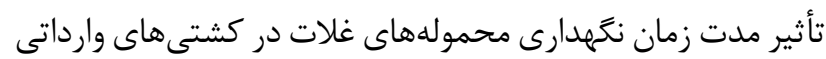

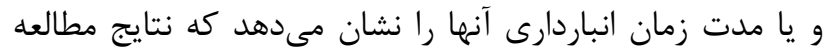
Najafian غلات، ماههاى گرم تابستان، كه رطوبت و دما بالاست را سيرى

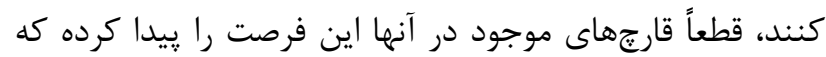
رشد كنند و توليد متابوليتهاى ثانويه در آنها صورت گيرد. Ranjbar قارعهاى آسيرزيلوس و آفلاتوكسين در فصل بهار و تابستان پايين مى آيد و در فصول ياييز و زمستان به دليل استفاده از خوارك دام انبار شده و عدم رعايت شرايط نتحهدارى مناسب در انبارها، ميزان

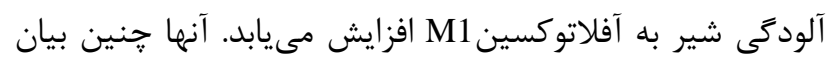

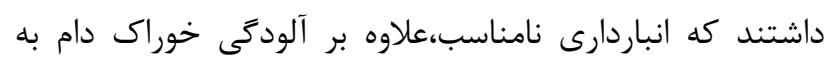

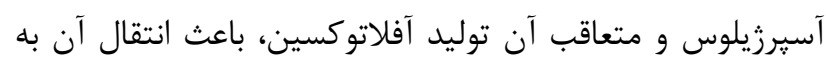

$$
\text { شيرهاى بسته بندى نيز مىشود (Y) (Y). }
$$

در اين مطالعه آسيرزيلوسهاى مستعد توليد توكسين از دانههاى برنج توليدى استان خوزستان(جميا و عنبربو) شناسايى و

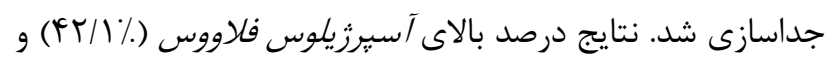
به دنبال آن آسبرزيلوس نيجر، آسيرزيلوس توبينجنسيس،

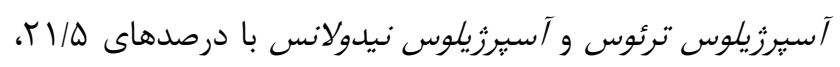
1ه/V

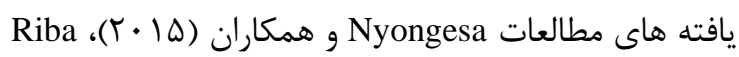

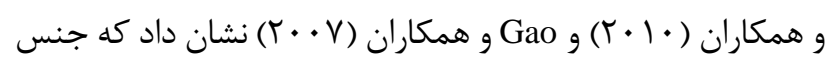

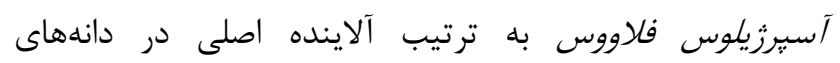
روغنى(يسته، بادام، فندق)، ذرت، گَندم و غلات و حبوبات است.

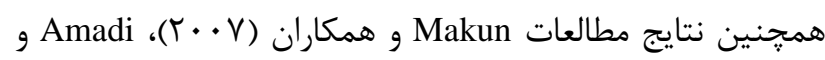

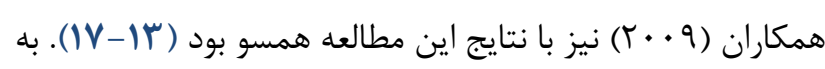

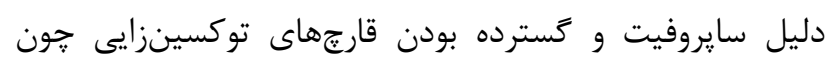
آسيرزيلوس، محصولاتى جون برنج و غلات از ابتدا داراى مقدارى

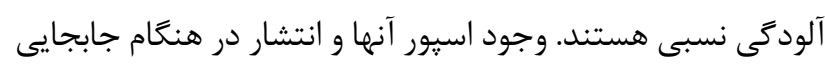

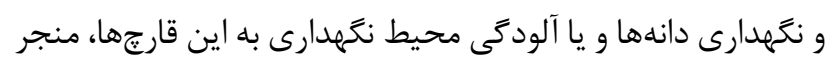

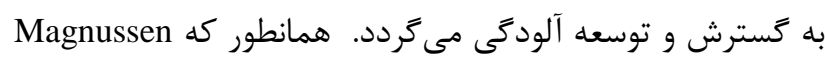

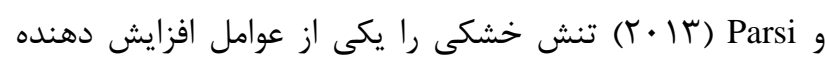

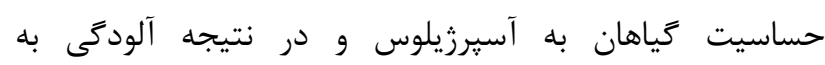
آفلاتوكسين دانستند (1))، نتايج حاصل از اين مطالعه نيز اين احتمال را مىدهد كه ميزان اين قارجها تحت شرايط با حرارت بالا

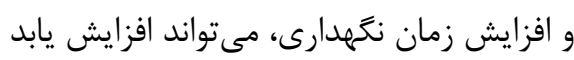

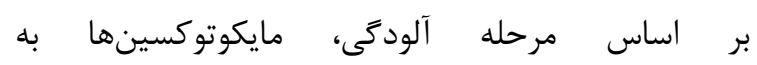

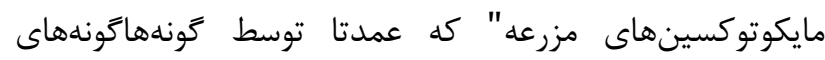
فوزاريوم توليد مىشوند و "مايكوتوكسين هاى انبار " كه در دوره منه

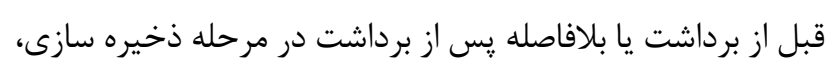

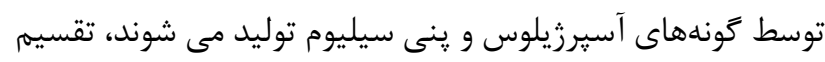

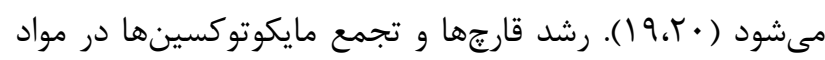
غذايى و خوراك دام تحت تأثير عوامل مختلفى است كه به طور 
است، كنترل آلودگى AFB1 در موادغذايى نياز به نظارت و كنترل

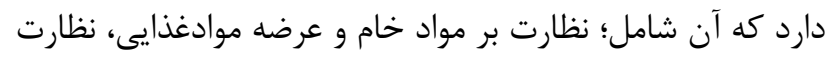
در طول فرآورى موادغذايى، نظارت بر محصولات نهايى و نيز ناريز

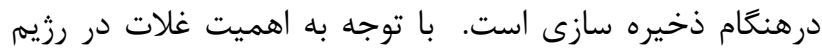

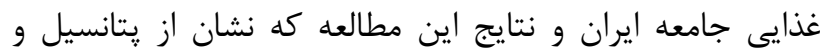

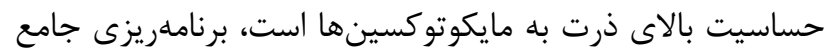
براى ايجاد سيستم عملياتى مناسب بلمنظور كاهش آلودكى

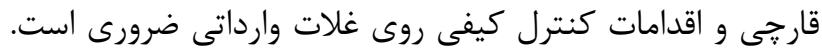

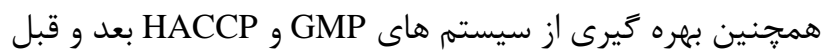
از برداشت سبب كاهش مايكوتوكسينها و عرصأ غذاى سالم به مصرف كننده خواهد شد.

$$
\text { تشكر و قدردانى }
$$

بدين وسيله نويسندًان اين مقاله بر خود لازم مى داند كه

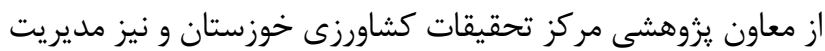
شركت يرهام جنوب كه در اين مطالعه با ما همكارى نمودند كمال تشكر و قدرانى را به عمل آورد.

$$
\text { تعارض منافع }
$$

\section{Referance}

1. Pleadin J, Vulic A, Persi N, Skrivanko M, Capek B, Cvetni Z. Aflatoxin B1 occurrence in maize sampled from Croatian farms and feed factories during 2013. Food Control. 2014; 40: 286-291 [DOI:10.1016/j.foodcont.2013.12.022]

2. Leslie, J. F., Bandyopadhyay, R. and Visconti, A.(Eds.). Mycotoxins: detection methods, management, public health and agricultural trade. 2008;CABI [DOI:10.1079/9781845930820.0000]

3. Alberts, J. F., Lilly, M., Rheeder, J. P., Burger, H. M., Shephard, G. S. and Gelderblom, W. C. A. Technological and community-based methods to reduce mycotoxin exposure. Food Control. 2017; 73: 101-109 [DOI:10.1016/j.foodcont.2016.05.029]

4. Abbas, H. K., Wilkinson, J. R., Zablotowicz, R. M., Accinelli, C., Abel, C. A., Bruns, H. A. and Weaver, M. A. Ecology of Aspergillus flavus, regulation of aflatoxin production, and management strategies to reduce
Cano-Sancho

كه حضور مايكوتوكسينها در مواد غذايى بستخى به بسيارى از شرايط از جمله فصل، آب و هوا (درجه حرارت، رطوبت)، منطقه مورد نظر، روش برداشت، ذخيرهسازى و :يردازش دارد (YV). Lahouar

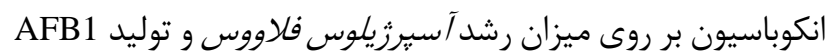

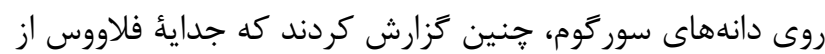

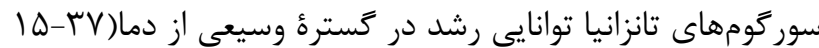
درجه سلسيوس) را دارد با اين حال توليد آفلاتوكسين در محدودة

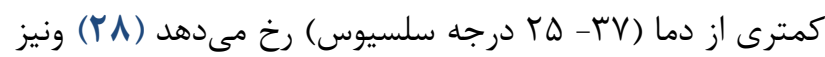
Ghali آفلاتوكسين در F T درجه سلسيوس رخ داده اما بيشترين رشد سوئٔ فلاووس در ها- درجه سلسيوس جr وجود داشته است (19).

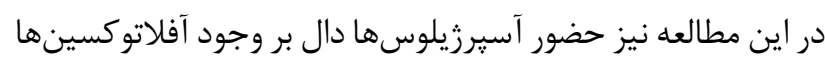

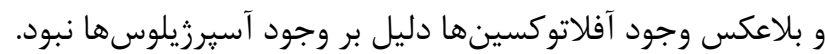
نقطه ضعف اين مقاله اين بود كه انتخاب نمونههاى برنج با روش در دسترس انجام شدهاست. هر جند مشخص گرديد كه نمونههاى

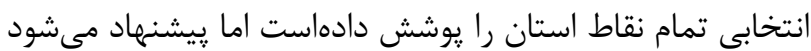

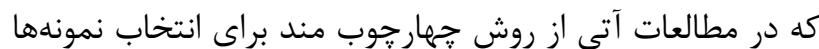
استفاده گردد.

\section{نتيجهَ'يرى:}

با توجه به حضور كستردهُ مايكوتوكسينها در مواد غذايى و مضرات آن، بويزه AFB1 كه يكى از آلايندههاى محصولات غذايى

aflatoxin contamination of corn. Toxin Reviews. 2009; 28(2-3): 142-153. [DOI:10.1080/15569540903081590]

5. Magnussen A, Parsi M.A. Aflatoxins, hepatocellular carcinoma and public health. World J Gastroenterol. 2013; 19(10): 1508. [DOI:10.3748/wjg.v19.i10.1508] [PMID] [PMCID]

6. Jinap S, De Rijk TC, Arzandeh S, Kleijnen HC, Zomer P, Van der Weg G, Mol JG. Aflatoxin determination using in-line immunoaffinity chromatography in foods. Food Control. 2012; 26(1): 42-48. [DOI:10.1016/i.foodcont.2011.12.007]

7. Pitt, J. I.: Hocking, A. D. Fungi and food spoilage. New York: Springer; 2009; 519. P. 275-33. [DOI:10.1007/978-0-387-92207-2_8]

8. Samson, R. A., Visagie, C. M., Houbraken, J., Hong, S. B., Hubka, V., Klaassen, C. H. and Varga, J. Phylogeny, identification and nomenclature of the genus 
Aspergillus. Studies in Mycology. 2014; 78: 141-173. [DOI:10.1016/j.simyco.2014.07.004] [PMID] [PMCID]

9. Samson RA, Noonim P, Meijer M, Houbraken JA, Frisvad JC, Varga J. Diagnostic tools to identify black aspergilli. Studies in mycology. 2007;59:129-45. [DOI:10.3114/sim.2007.59.13] [PMID] [PMCID]

10. Gupta VK (Ed). New and future developments in microbial biotechnology and bioengineering: Aspergillus system properties and applications. Elsevier; 2016.

11. Mehrabi-Koushki, M. Bavarsad, M., Farrokhinejad, R., Jamshidi, J. and Alimohammadi, A. The comparison of ITS-rDNA and tefl $\alpha$ genomic regions for phylogenetic study of some Trichoderma Species. Iranian Journal of Plant Protection Science.2016; 47, 61-70. [ In Persian]

12. Raeder U. and Broda P. Rapid preparation of DNA from filamentous fungi. Letters in Applied Microbiology. 1985;1: 17-20. [DOI:10.1111/j.1472765X.1985.tb01479.x]

13. Nyongesa, B. W., Okoth, S. and Ayugi, V. Identification Key for Aspergillus Species Isolated from Maize and Soil of Nandi County, Kenya. Advances in Microbiology. 2015; 5(04): 205-229 [DOI:10.4236/aim.2015.54020]

14. Riba A, Bouras N, Mokrane S, Mathieu F, Lebrihi A, Sabaou N. Aspergillus section Flavi and aflatoxins in Algerian wheat and derived products. Food and Chemical Toxicology. 2010; 48(10): 2772-2777 [DOI:10.1016/j.fct.2010.07.005] [PMID]

15. Gao, J., Liu, Z. and Yu, J. Identification of Aspergillus section Flavi in maize in northeastern China. Mycopathologia. 2007;164(2): 91-95. [DOI:10.1007/s11046-007-9029-4] [PMID]

16. Makun, H. A., Gbodi, T. A., Akanya, O. H., Salako, E. A. and Ogbadu, G. H. Fungi and some mycotoxins contaminating rice (Oryza sativa) in Niger state, Nigeria. African Journal of Biotechnology. (2007);6(2):99-108

17. Amadi, J. E. and Adeniyi, D. O. Mycotoxin production by fungi isolated from stored grains. African Journal of Biotechnology. 2009; 8(7):1219-1221

18. Magnussen A, Parsi M.A. Aflatoxins, hepatocellular carcinoma and public health. World J Gastroenterol. 2013; 19(10): 1508. [DOI:10.3748/wig.v19.i10.1508] [PMID] [PMCID]

19. Hassan ZU, Al-Thani RF, Migheli Q, Jaoua S. Detection of toxigenic mycobiota and mycotoxins in cereal feed market. Food Control. 2018; 84: 389-394. [DOI:10.1016/j.foodcont.2017.08.032]

20. 20- Reiter E.V, Vouk F, Bohm J, Razzazi-Fazeli E. Aflatoxins in rice - A limited survey of products marketed in Austria. Food Control. 2010; 21(7): 988991. [DOI:10.1016/j.foodcont.2009.12.014]
21. Ghali, R., Khlifa, K. H., Ghorbel, H., Maaroufi, K. and Hedilli, A. Aflatoxin determination in commonly consumed foods in Tunisia. J Sci Food Agric. 2010; 90(14): 2347-2351. [DOI:10.1002/jsfa.4069] [PMID]

22. Mazaheri M, MahmoudiMaymand M. Investigation of Aflatoxins in Imported Animal Feeds in Iran. Iranian Journal of Toxicology. 2018;12(6):33-8.

23. Amanloo S, Rezaei Kahhka MR, Ramezani AA, Mir L (2014) .The Mycotoxin contamination of the imported consumer rice and its producing fungi in Zabol . Journal of Jahrom University of Medical Sciences. 12(1): 17-25. [In Persian] [DOI:10.29252/jmj.12.1.17]

24. Farahmandfar R, Rashidaei Abandansari S, Maghsoudlou E, Asnaashari M. Determination of mycotoxin contamination in imported wheat to Mazandaran province by high performance liquid chromatography. Iranian Journal of Health and Environment. 2018;11(1):15-24.

25. Najafian M. Comparison the level of Aflatoxin in different varieties of internal and imported rice in different collection seasons and effect of cooking methods on the level of toxins. 2014; 6(4): 328-336. [In Persian]

26. Ranjbar S, Noori M, Nazari R. Study of milk aflatoxin M1 and its relationship with feed fungi flora in Markazi Province. J Cell Tissue. 2010; 1(1): 9-18. [In Persian]

27. Cano-Sancho G, Sanchis V, Marin S, Ramos A.J. Occurrence and exposure assessment of aflatoxins in Catalonia (Spain). Food and Chemical Toxicology. 2013; 51: 188-193. [DOI:10.1016/j.fct.2012.09.032] [PMID]

28. Lahouar, A., Marin, S., Crespo-Sempere, A., Saïd, S. and Sanchis, V. Effects of temperature, water activity and incubation time on fungal growth and aflatoxin B1 production by toxinogenic Aspergillus flavus isolates on sorghum seeds. Revista Argentina de Microbiología. 2016; 48(1): 78-85. [DOI:10.1016/j.ram.2015.10.001] [PMID] 